\title{
بناء مقياس مهارات الاتصال بين حارس المرمى ولاعبى خط الدفاع فى كرة القدم
}

\author{
د. محمد الشحات إبراهيم على \\ مدرس بقسم علم النفس الرياضى الرئي \\ كلبة التربية الرياضية الفية الرياضية \\ جامعة المنصورة النرياضية
}

1/1/ المقدمة ومشكلة البحث:

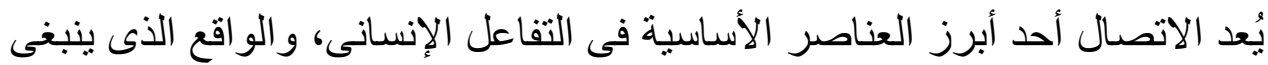

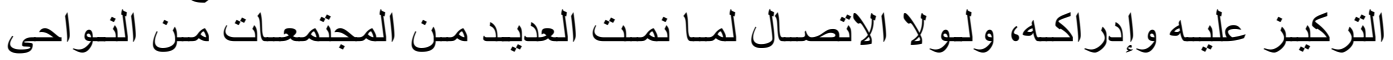

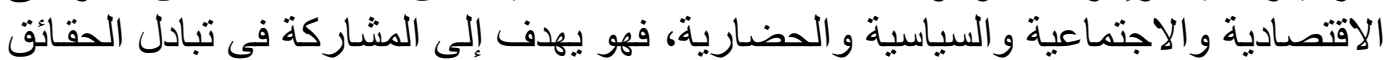

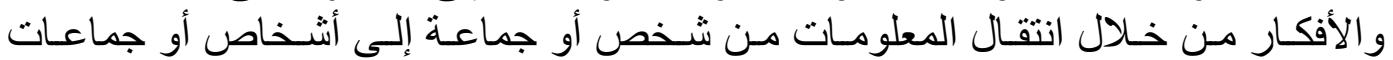

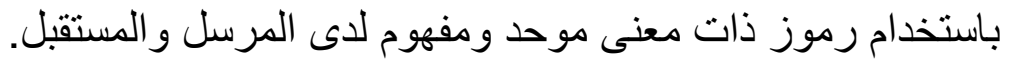

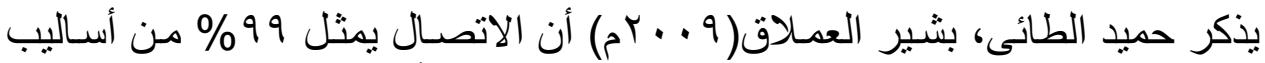

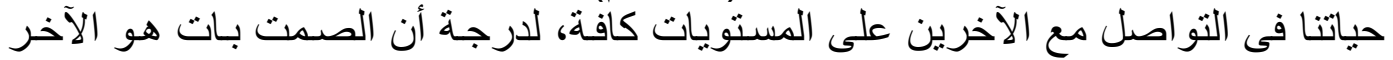

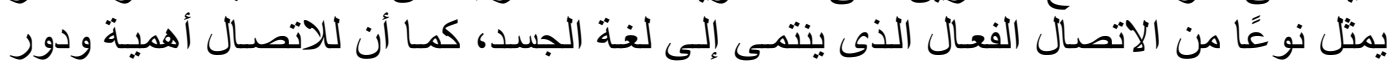

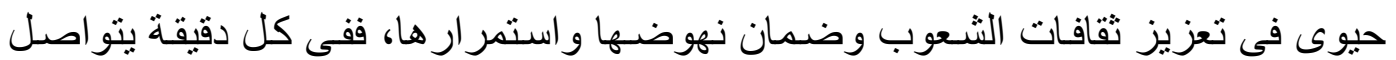

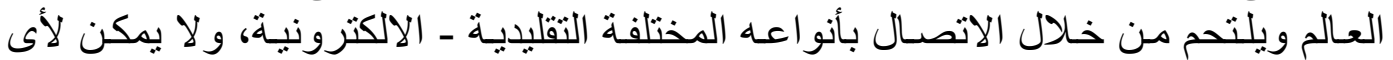

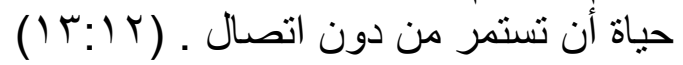

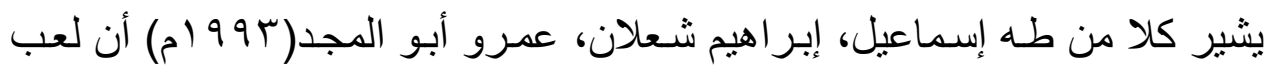

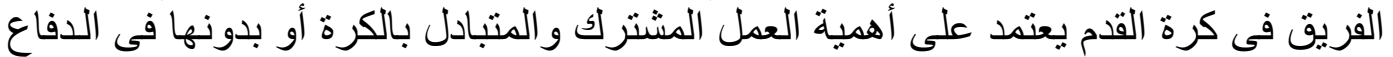

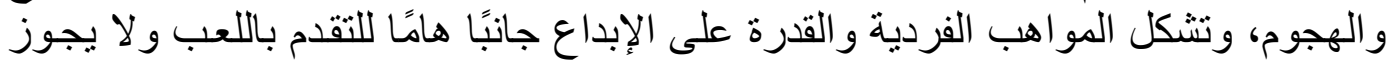

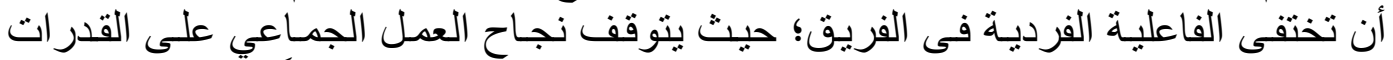

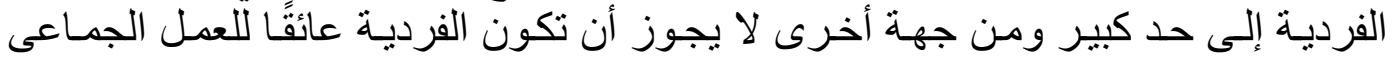

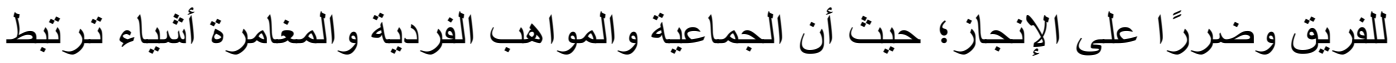
بعضها بالبعض الأخر وتتداخل معا لسير اللعب بطريقة جيدة وبفعل فريق جيد. (7 ( 9 (1)

تؤكد إخلاص عبد الحفيظ(r + . r م) على أن معظم الأنشطة الرياضية حتى الفرديـة

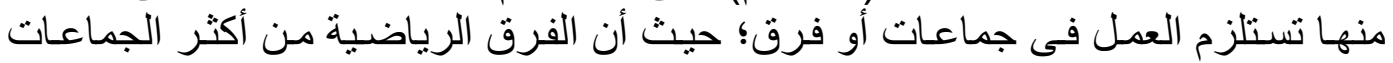

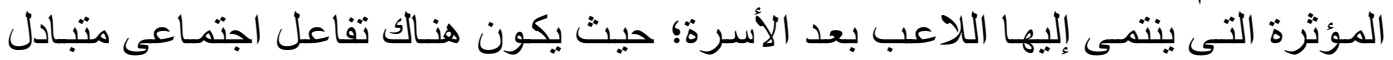

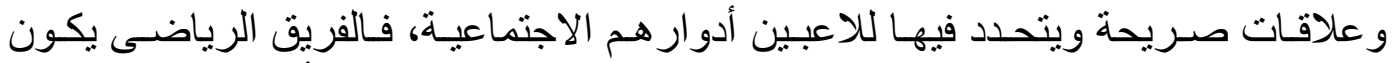

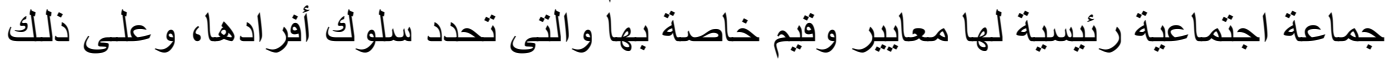

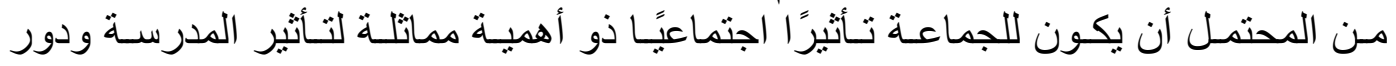

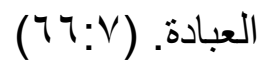

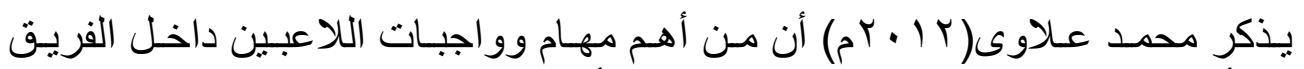

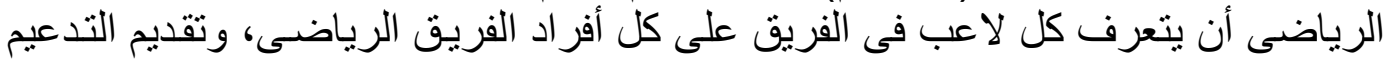




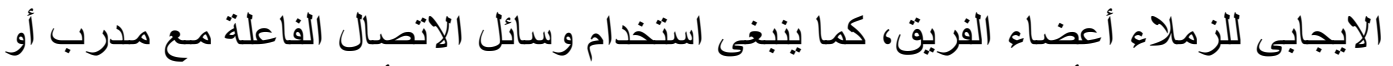

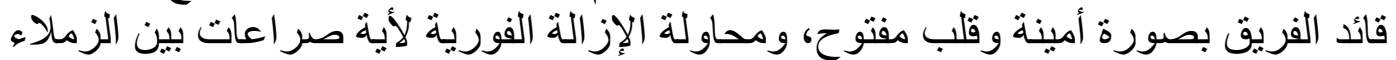

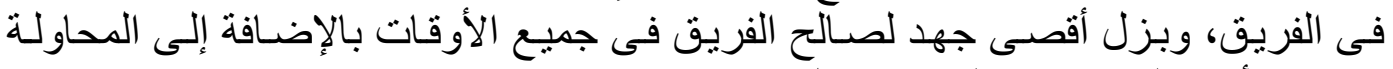

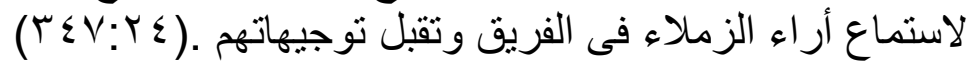

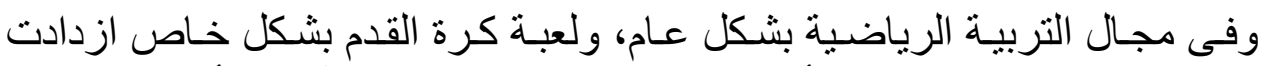

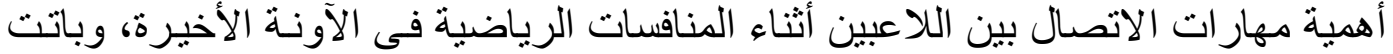

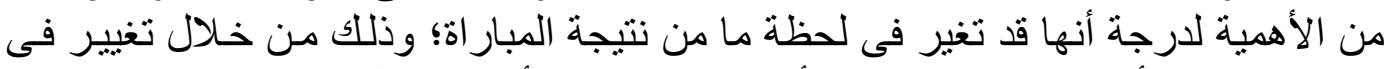

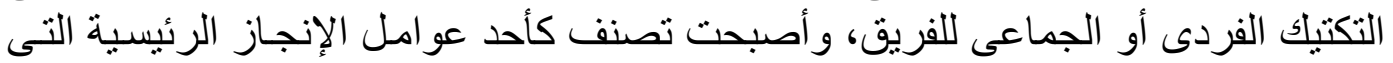

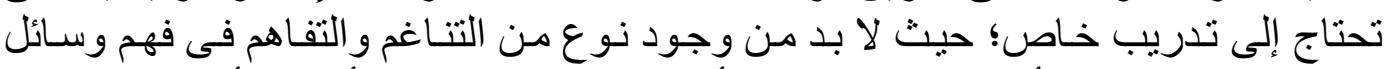

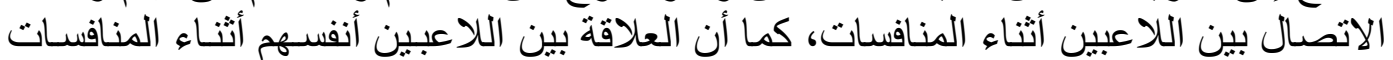

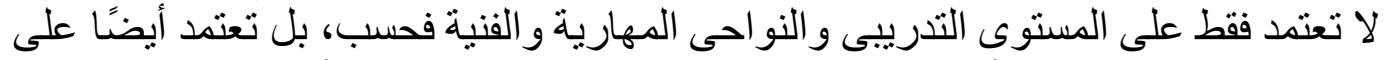

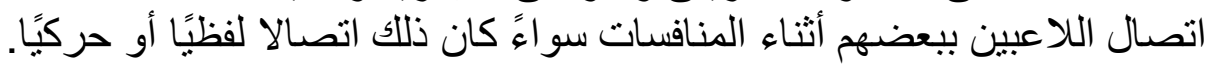

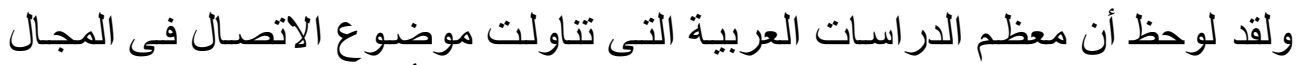

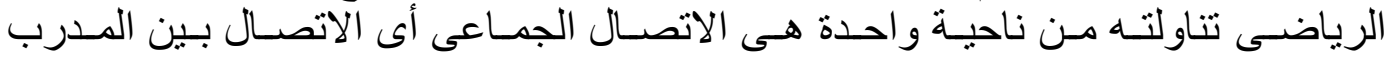

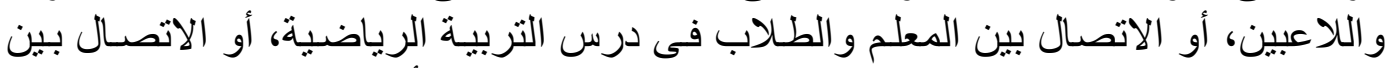

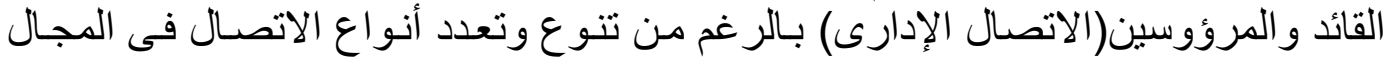

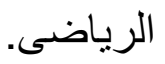

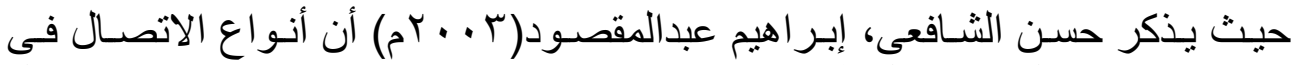

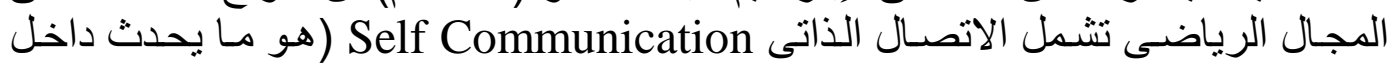

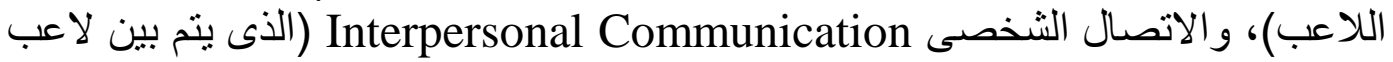

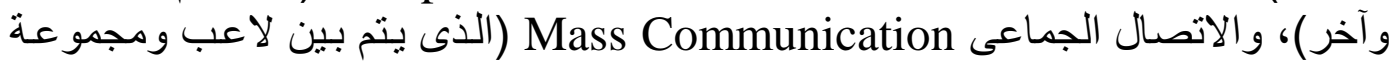

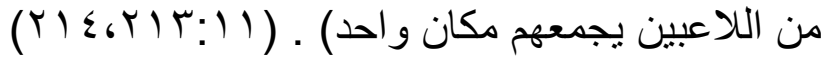

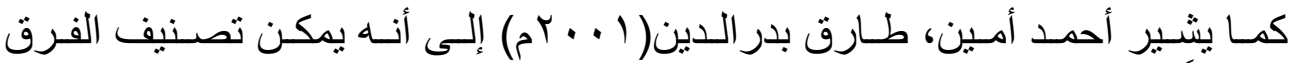

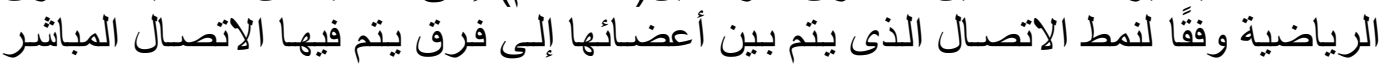

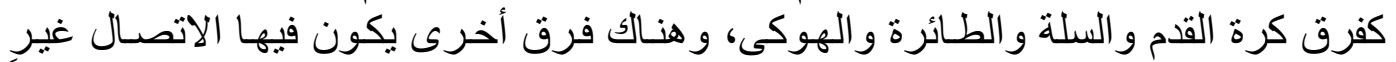

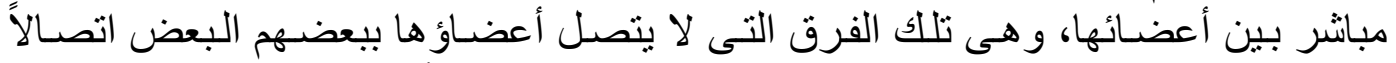

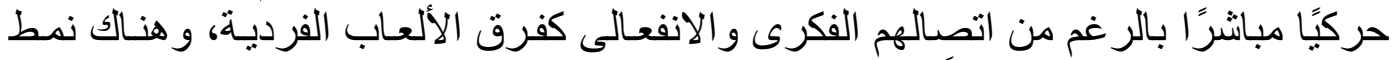

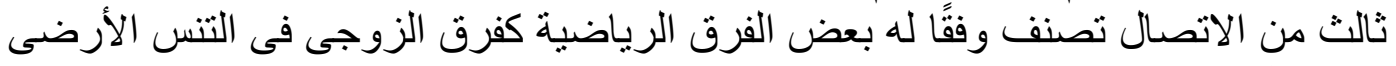

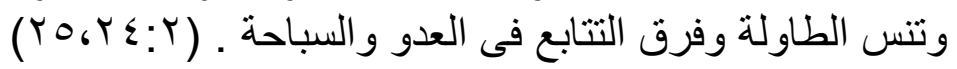

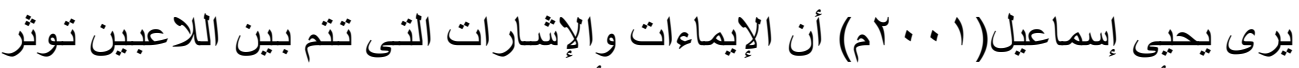

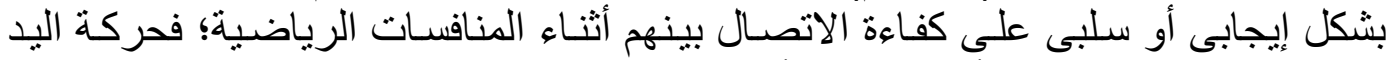

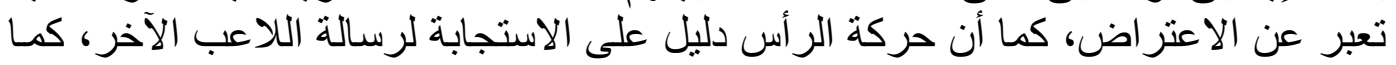

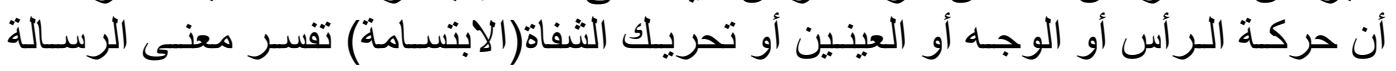


الاتصالية؛ فالابتسامة تعنى استحسان سلوك الزميل، وكذللك نغمة أو طبقة الصوت لها لها دور

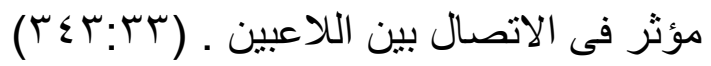

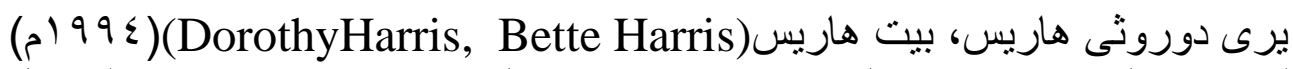
أن عملية الاتصال تتضمن الإرسال هاري هارئ Sending، والاستقبال Receiving، وتفسير الرسائل Messages Interpreting اللاعبين على الاتصـال اللفظى لerbal Communication و و الاتصـال غير اللفظى الاتصى

$(10 \cdot: r \varepsilon)$. Non-Verbal Communication

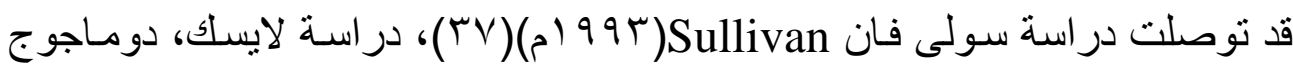
دالق Lausic, Domagoj

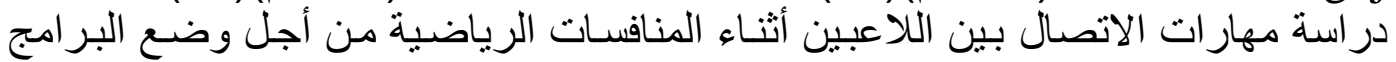

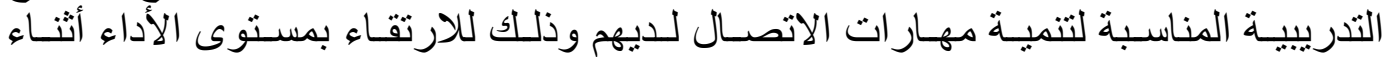

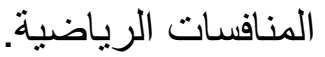

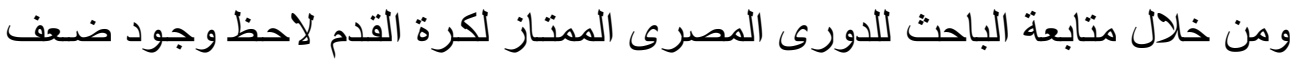

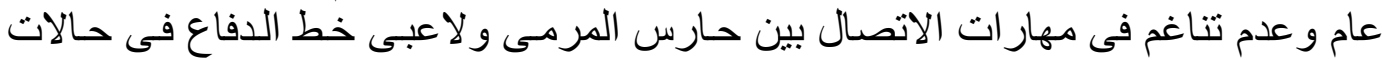

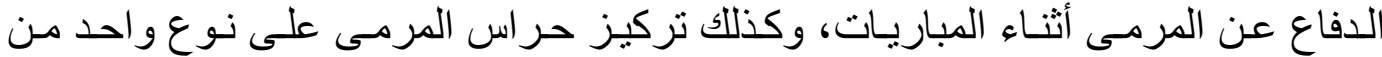

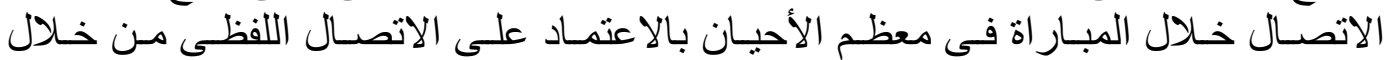

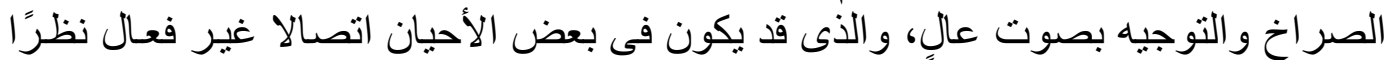

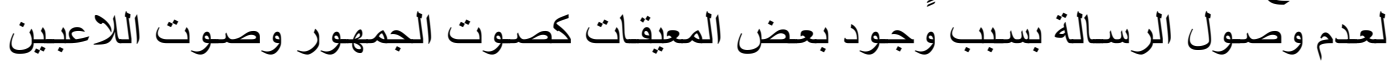
المنافسين ..... و غير ها من مشتتات الانتباه أثناء المبار الته

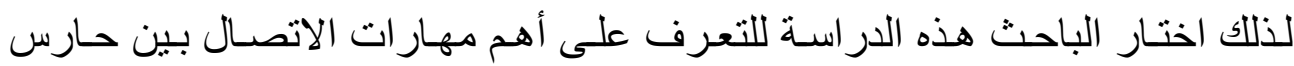

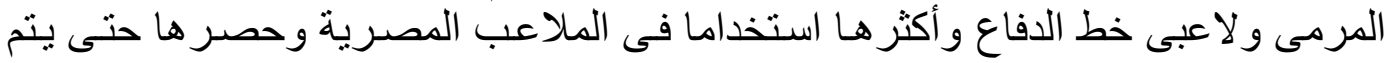

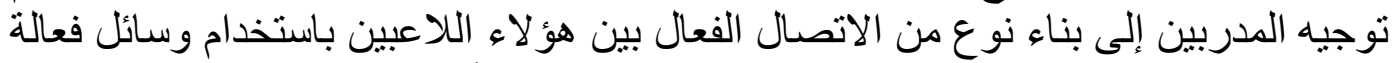

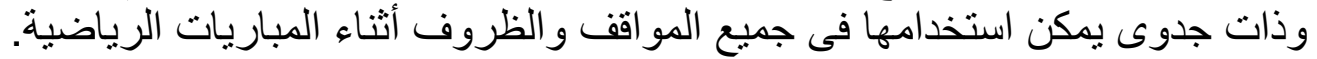

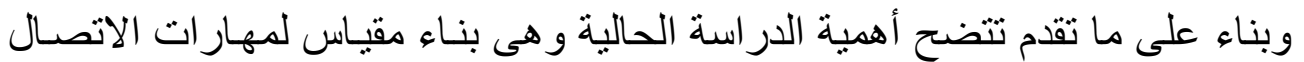

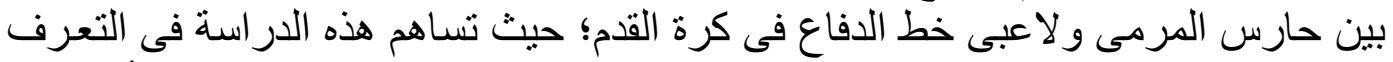

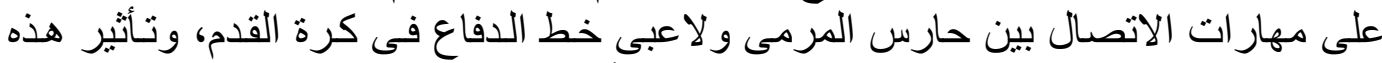

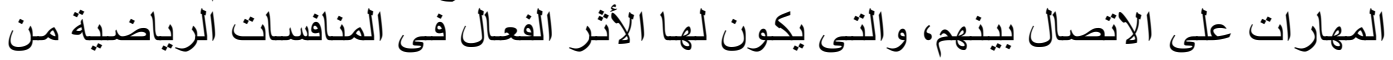

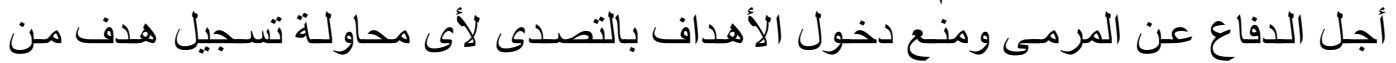

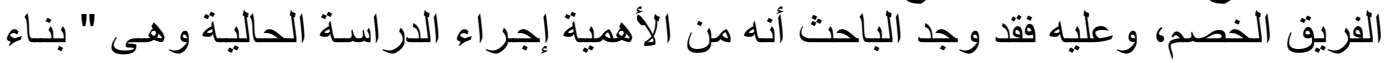
مقياس مهار ات الاتصال بين حارس المرمى و لاعبى الاهي خط الدفاع في كرة القدم. 


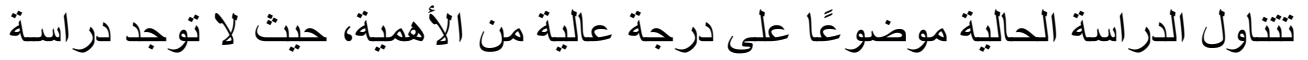

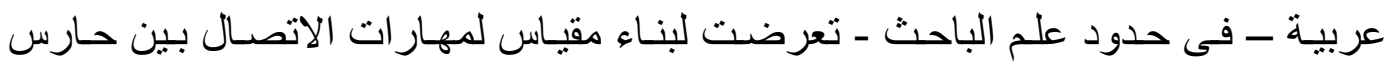

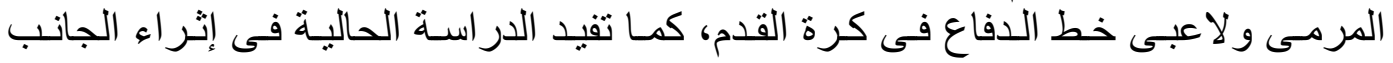
النظرى للار اسات و البحوث المتعلقة بمهار ات الاتصال في المجال الرياضى الرئ.

(الأهمية التطبيقية للبحث:

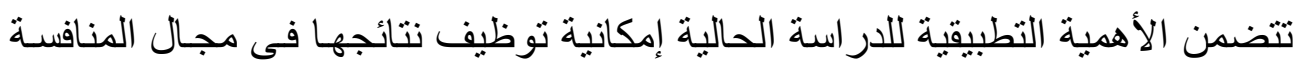

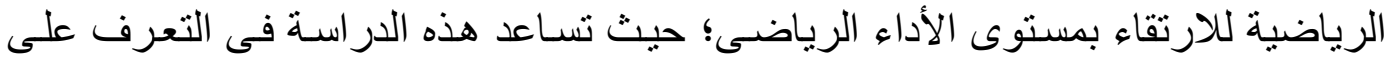

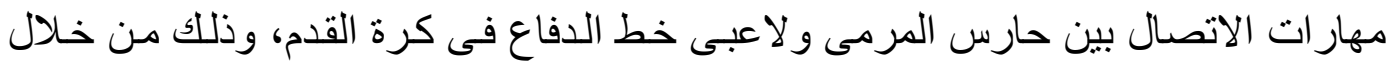

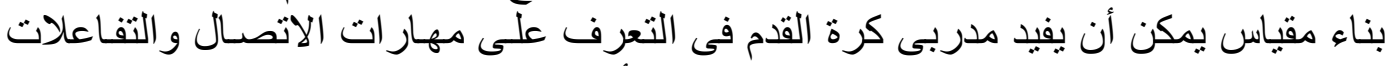

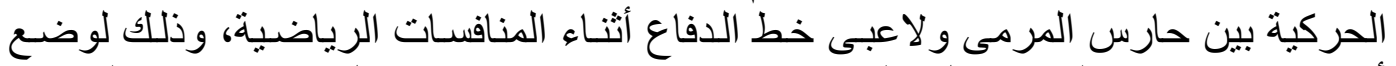

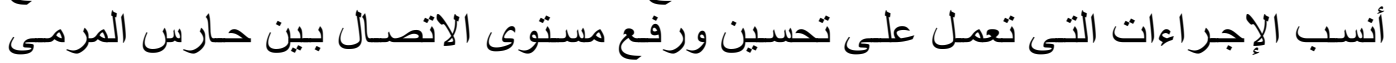
و لاعبى خط الدفاع أثناء هذه المنافسات من أجل الدفاع عن المرمى.

يهدف البحث إلى بنـاء مقياس مهار ات الاتصـال بين حارس المرمى و لاعبى خط

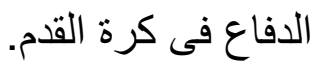

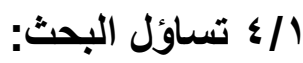

ما هى مهار ات الاتصال بين حارس المرمى و لاعبى خط الدفاع فى كرة القدج؟. | - | (10 مصطلحات البحث:

Communication Skills 1/0/1 مهارات الاتصال: 1/1/

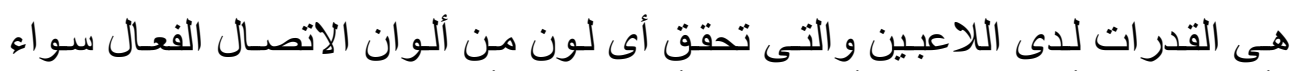

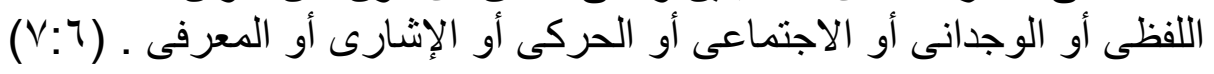


جاول (1)

1/ا الاراسات المرجعية :

الاراسات المرجعية

\begin{tabular}{|c|c|c|c|c|c|c|c|}
\hline \multirow[b]{2}{*}{ أهم الاستتتاجات } & \multicolumn{2}{|c|}{ ألجراسة } & \multirow{2}{*}{ أهم أهداف الاراسة } & \multirow{2}{*}{$\begin{array}{l}\frac{3}{2} \\
\frac{3}{3} \\
\frac{3}{3} \\
.2\end{array}$} & \multirow{2}{*}{ عنوان الدراسة } & \multirow[b]{2}{*}{ اسم الباحث } & \multirow[b]{2}{*}{ p } \\
\hline & 蛋 & $\overline{\bar{s}}$ & & & & & \\
\hline 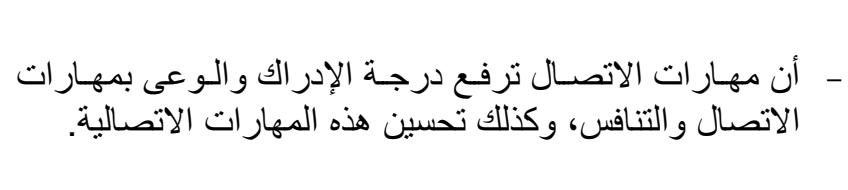 & 可 & $\begin{array}{l}\dot{x} \\
\ddot{y} \\
g\end{array}$ & - الاتصال لإى لاعبى الفرق الجماعية. & $\begin{array}{l}\frac{1}{1} \\
\frac{4}{2} \\
y\end{array}$ & 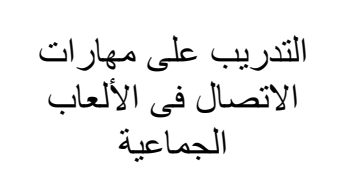 & 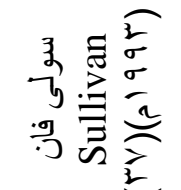 & 1 \\
\hline 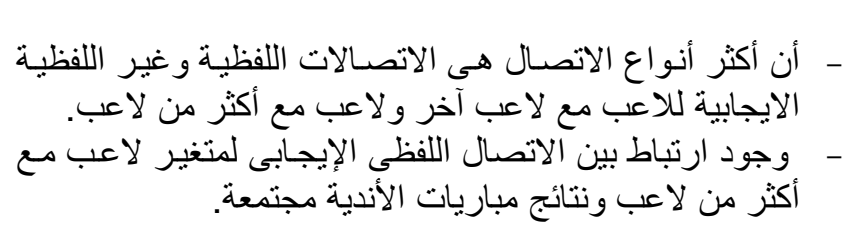 & के & 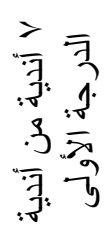 & - & 童. & 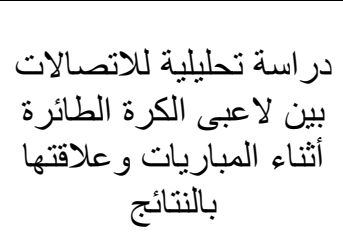 & $\begin{array}{l}3 \\
3= \\
0 \\
1 \\
3 \\
3 \\
3=\end{array}$ & r \\
\hline 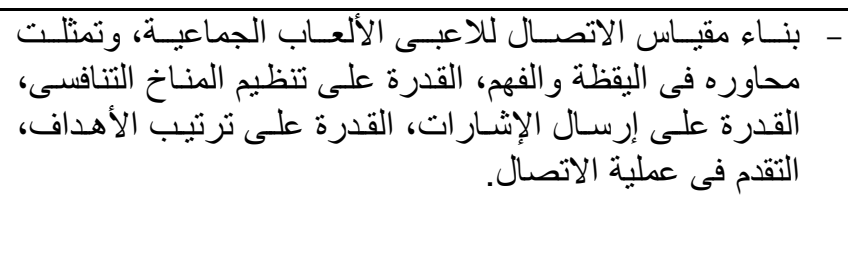 & के & $\begin{array}{l}\dot{v} \\
\ddot{z} \\
\ddot{g}\end{array}$ & | الجماعية. & $\begin{array}{l}30 \\
\frac{9}{3} \\
3\end{array}$ & ل العبى الألعاب الجماعية & 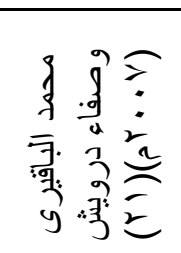 & $r$ \\
\hline
\end{tabular}


تابع جدول (1)

الار اسات المرجعية

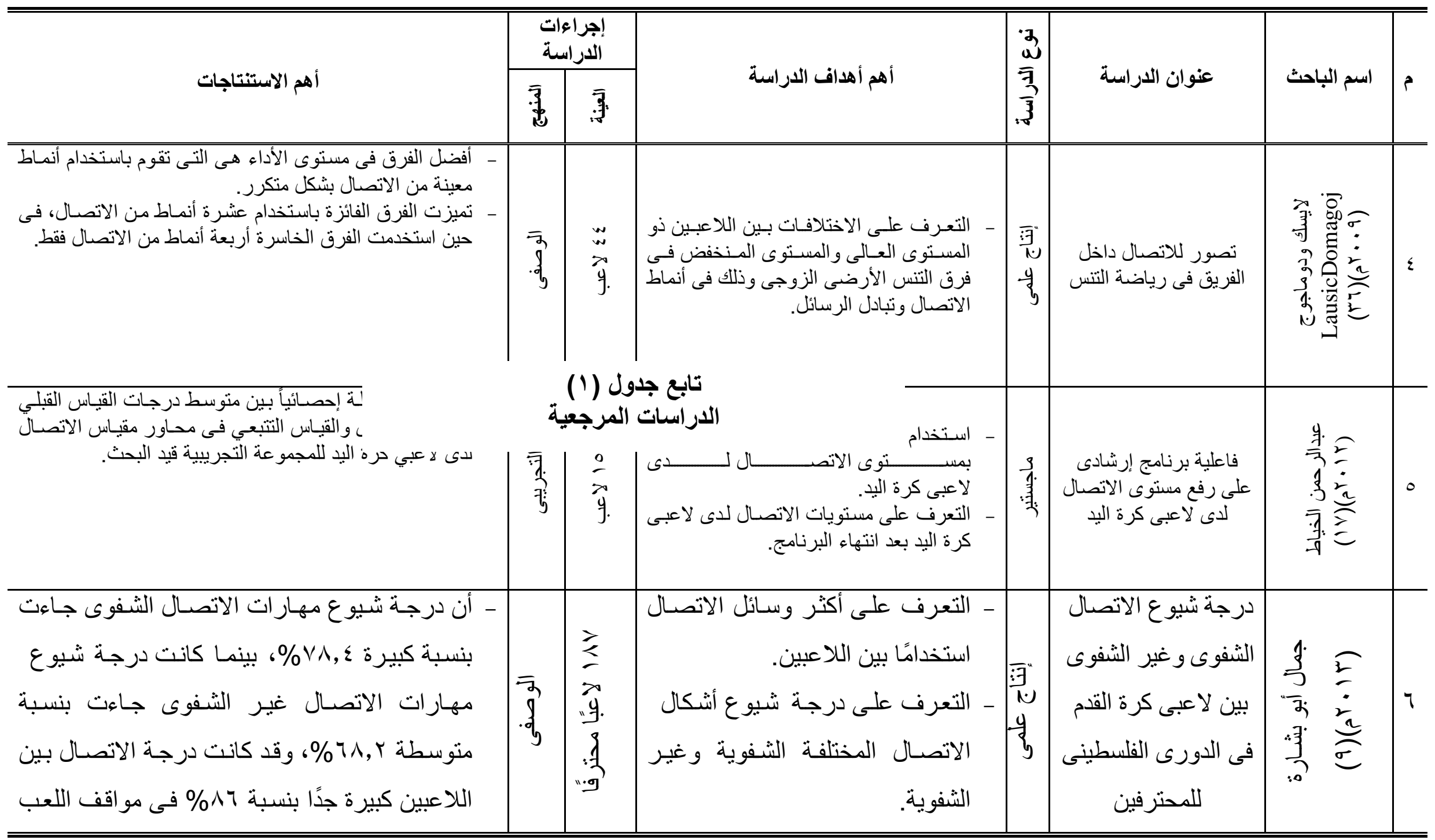




\begin{tabular}{|c|c|c|c|c|c|c|c|}
\hline \multirow[b]{2}{*}{ أهم الاستنتاجات } & \multicolumn{2}{|c|}{ ألإراساتة } & \multirow{2}{*}{ أهم أهداف الدراسة } & \multirow{2}{*}{$\begin{array}{l}3 \\
\frac{3}{3} \\
\frac{7}{3} \\
\frac{3}{3}\end{array}$} & \multirow{2}{*}{ عنوان الدراسة } & \multirow{2}{*}{ اسم الباحث } & \multirow[b]{2}{*}{ b } \\
\hline & & $\overline{\text { 事 }}$ & & & & & \\
\hline 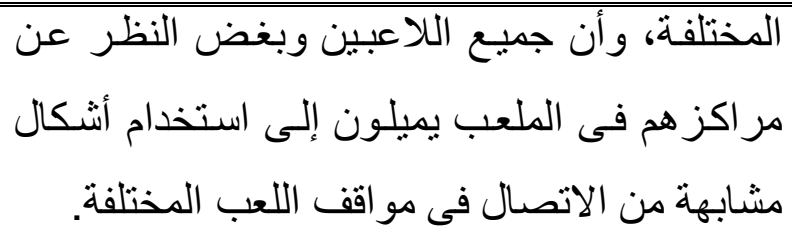 & & & 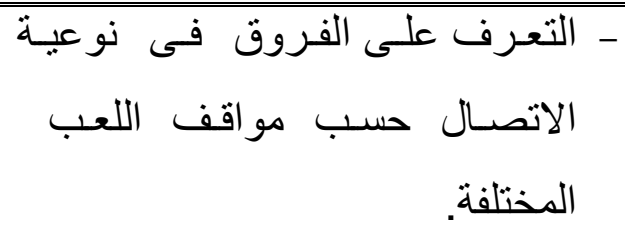 & & & & \\
\hline
\end{tabular}




$$
\text { I/V/ إجراع البحث: البحث: }
$$

استخدم الباحث المنهج الوصفى(الأسلوب المسحى)، وذللك لملاءمته لطبيعة وهدف البحث عن طريق وصف ما هو كائن وتحليله واستخلاص الاسلفال الحقائق منه.

اشتنمل مجتمع البحث على على لاعبى كرة القدم المقيدين بسجلات الاتحاد المصرى لكرة القدم

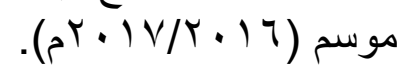

T/V/

اشتملت عينة البحث على بـ ه لاعبًا من لاعبى كرة القدم تم اختيار هم بطريقة عمدية من

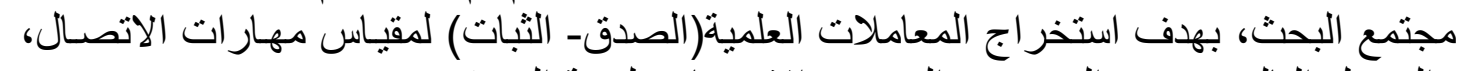

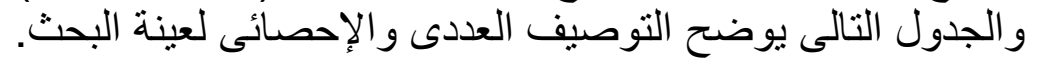

\begin{tabular}{|c|c|c|c|c|c|}
\hline \multicolumn{5}{|c|}{ النــادى } & \multirow[b]{3}{*}{ r } \\
\hline \multirow[b]{2}{*}{ عدد اللاعبين } & \multicolumn{2}{|c|}{ مراكز اللاعبين } & \multirow[b]{2}{*}{ المستوى } & \multirow[b]{2}{*}{ اسم النادى } & \\
\hline & مدافع & حرمى & & & \\
\hline V & $\varepsilon$ & $r$ & ممتاز ب & نادى غزل المحلة & 1 \\
\hline$\Lambda$ & 0 & $r$ & ممتاز ب & نادى نبروة & $r$ \\
\hline V & $r$ & $\varepsilon$ & ممتاز ب & نادى شربين & $r$ \\
\hline 7 & $\varepsilon$ & $r$ & درجة ب & نادى بنى عبيد & $\varepsilon$ \\
\hline 9 & 7 & $\mu$ & درجة r & نادى ميجا سبورت & 0 \\
\hline$\Lambda$ & 0 & $r$ & درجة & نادى بلقاس & 7 \\
\hline$V$ & $\varepsilon$ & $r$ & درجة ع & نادى سماد طلخا & $\mathrm{V}$ \\
\hline or & rI & YI & - & V & الكجموع \\
\hline
\end{tabular}

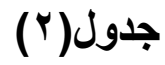

التوصيف العددى والإحصائى لعينة البحث

أسباب اختيار عينة البحث:

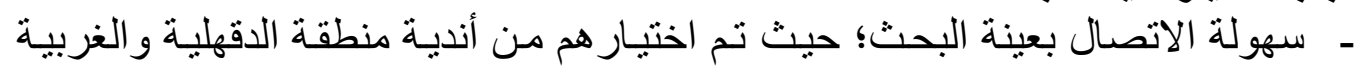
لكرة القدم حتى يسهل التجمع و التطبيق. 


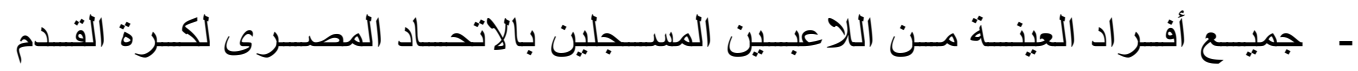

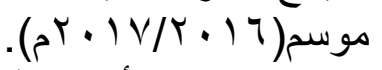

- مو افقة مدربى الأندية على تطبيق المقياس قيد البحث.

ه/V/ أدوات جمع البيانات:

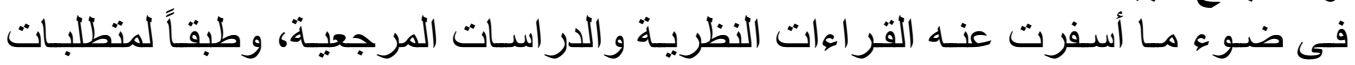

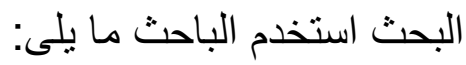

إعاد الإس مهارات الاتصال بين حارس المرمى ولاعبى خط الدفاع فى كرة القدم : إعداد/ الباحث دهار

1///0/V//

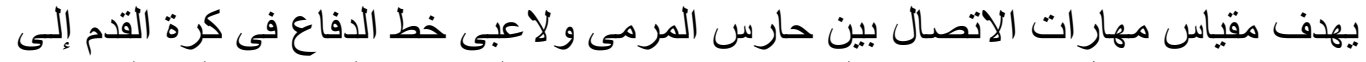

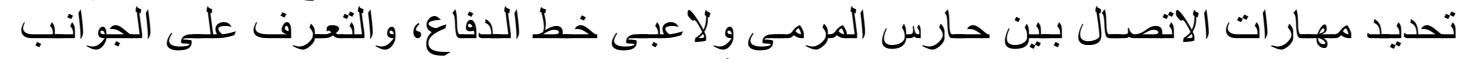
الايجابية والسلبية فى عملية الاتصال فيما بينهم أثناء المنافسات الرياضية الرية.

( 1/ 1/ / تحديد مهارات المقياس:

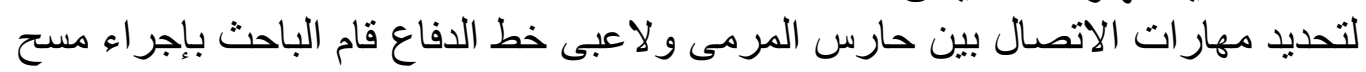

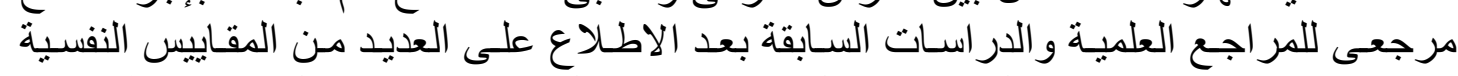

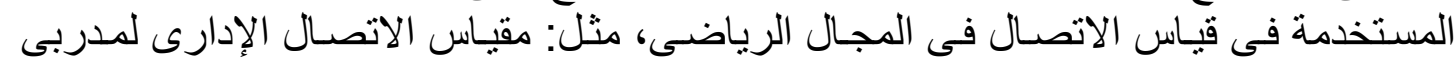

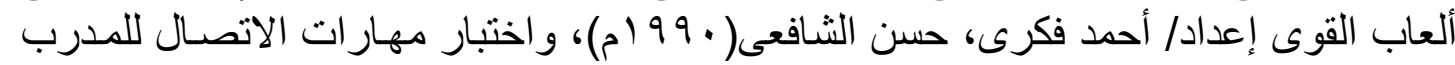

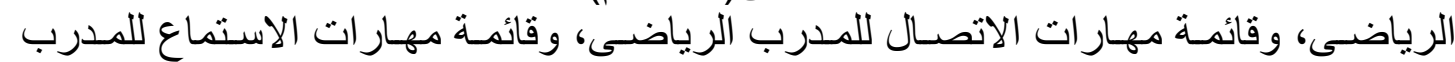

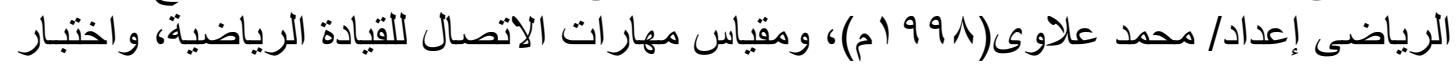

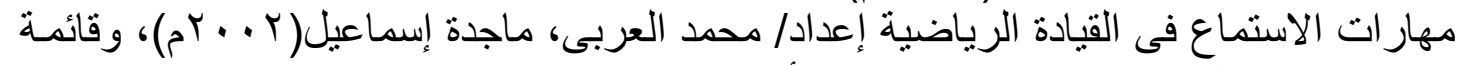

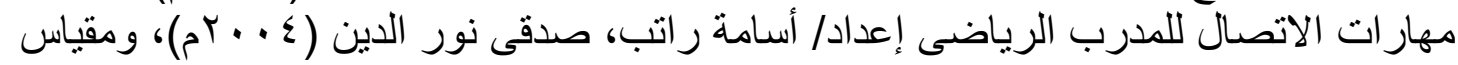

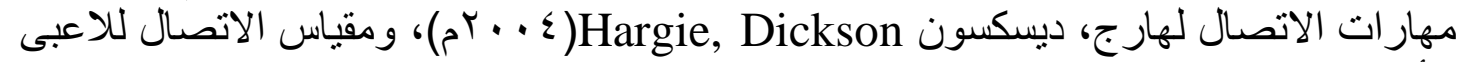

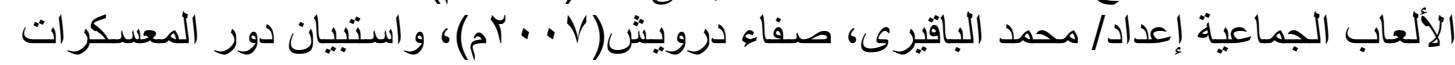

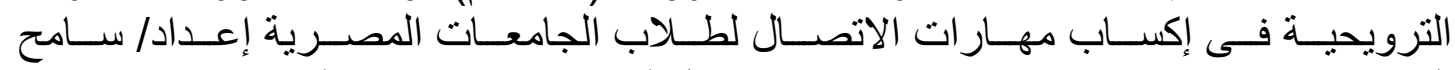

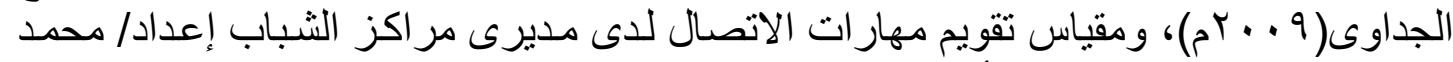

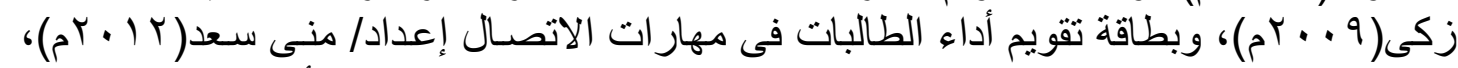

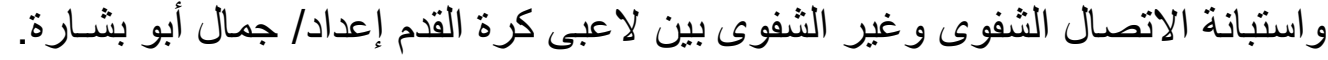

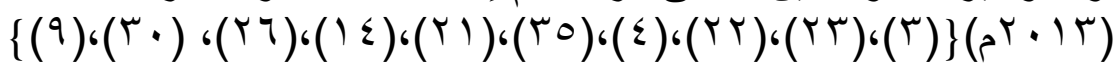

وقد أظهر المسح المرجعى الذى قام بـه الباحث ع ب مهارة للاتصـال بشكل عام والتى تتضح فى الجدول التالى رقم(ب). 
جدول(r)

المسح المرجعى لمهارات الاتصال

\begin{tabular}{|c|c|c|c|c|c|c|c|c|c|c|c|c|c|c|c|c|c|c|c|c|c|c|c|c|c|c|c|c|c|}
\hline \multicolumn{25}{|c|}{ مهارات الاتصال } & \multicolumn{3}{|c|}{ بيانات عن المرجع } & \multirow[b]{2}{*}{ اسم المـؤلف } & \multirow[b]{2}{*}{ b } \\
\hline 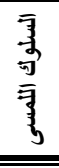 & 司 & $\overline{\frac{1}{3}}$ & $\begin{array}{l}\overline{\overline{3}} \\
3 \\
\bar{u} \\
\bar{a} \\
\overline{7}\end{array}$ & 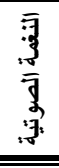 & 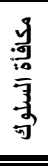 & 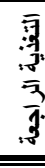 & $\begin{array}{l}\overline{3} \\
\end{array}$ & 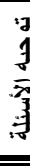 & & & 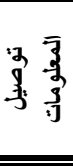 & $\begin{array}{l}3 \\
\frac{3}{3} \\
\frac{3}{3}\end{array}$ & 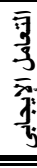 & 鹤 & $\begin{array}{l}3 \\
3 \\
3 \\
3 \\
3 \\
3 \\
3\end{array}$ & 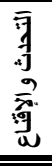 & 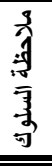 & 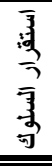 & $\begin{array}{l}\text { 氛 } \\
\text { 商 } \\
\end{array}$ & 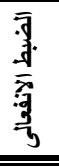 & $\begin{array}{l}\overline{3} \\
\overline{3} \\
\overline{3}\end{array}$ & 裏 & 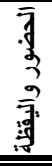 & 司 & 次凫 & 国哥 & 活牙 & & \\
\hline & & & $\checkmark$ & & & & & & & & & & & & & $\checkmark$ & & & & & & & & $\checkmark$ & ryo & $r$. & $\begin{array}{ll}1999 \\
\end{array}$ & فتحى مصطفى الزيات & .1 \\
\hline & & & & & & & & & & & & & & & & & & & & & $\checkmark$ & $\checkmark$ & & & $\varepsilon r$ & $r$ & 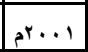 & أحدد أمين فوزى، وطارق محمد بدر اللين &.$r$ \\
\hline \multirow[t]{11}{*}{$\checkmark$} & & & $\checkmark$ & $\checkmark$ & & & & & & & & $\checkmark$ & $\checkmark$ & & & & & $\checkmark$ & $\checkmark$ & & & & & & $1 . \varepsilon$ & $\varepsilon$ & \begin{tabular}{|l|l|} 
prol \\
\end{tabular} & أسامه كامل راتب &.$r$ \\
\hline & & & & & & & & & & & & & & & & & & & & & $\checkmark$ & & & $\checkmark$ & ov & 1 & |r...r & أحمد أمين فوزى & . \\
\hline & & & $\checkmark$ & $\checkmark$ & $\checkmark$ & & & & & & $\checkmark$ & $\checkmark$ & $\checkmark$ & $\checkmark$ & & & & $\checkmark$ & $\checkmark$ & & & & $\checkmark$ & & ro & rr & $\left|a^{2} \ldots r\right|$ & و ائل رفاعى إبراهيم & .0 \\
\hline & & & $\checkmark$ & & $\checkmark$ & & & & & & $\checkmark$ & $\checkmark$ & $\checkmark$ & & & & & $\checkmark$ & $\checkmark$ & & & & & & $\varepsilon$. & 0 & 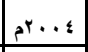 & أسامه كامل راتب & .9 \\
\hline & & $\checkmark$ & $\checkmark$ & $\checkmark$ & & & $\checkmark$ & $\checkmark$ & & & $\checkmark$ & & $\checkmark$ & $\checkmark$ & $\checkmark$ & $\checkmark$ & & & & $\checkmark$ & & $\checkmark$ & $\checkmark$ & $\checkmark$ & rov & ir & 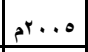 & خالد يوسف الزغبي &. $\mathrm{V}$ \\
\hline & & & & $\checkmark$ & & & 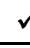 & 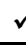 & & & $\checkmark$ & $\checkmark$ & & $\checkmark$ & $\checkmark$ & $\checkmark$ & $\checkmark$ & $\checkmark$ & & $\checkmark$ & $\checkmark$ & & $\checkmark$ & $\checkmark$ & $r$ & ra & pr... & محمود محمد محمود &.$\wedge$ \\
\hline & & & $\checkmark$ & & & & & & & & & & & $\checkmark$ & & & $\checkmark$ & $\checkmark$ & $\checkmark$ & $\checkmark$ & & $\checkmark$ & $\checkmark$ & & $r \wedge$ & 11 & 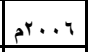 & عماد عيد عبيد & .9 \\
\hline & & & $\checkmark$ & $\checkmark$ & $\checkmark$ & & v & v & & & $\checkmark$ & $\checkmark$ & $\checkmark$ & $\checkmark$ & & & $\checkmark$ & & $\checkmark$ & $\checkmark$ & $\checkmark$ & $\checkmark$ & $\checkmark$ & & $1 \%$ & ro & 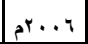 & محمد عبد الله الكميتى & .1. \\
\hline & & & & & & & & & & & & & & & & & & & & & $\checkmark$ & & & & ret & 19 & pr..vv & عمرو حسن بدران & 11 \\
\hline & & & & & & $\checkmark$ & $\checkmark$ & & & & & & & & & & & & & & & & & & ro & $\Lambda$ & 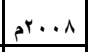 & ثابت عبد الرحمن إدريس & $.1 r$ \\
\hline & $\checkmark$ & $\checkmark$ & & & & & $\checkmark$ & $\checkmark$ & & & $\checkmark$ & $\checkmark$ & $\checkmark$ & $\checkmark$ & $\checkmark$ & $\checkmark$ & & & & $\checkmark$ & $\checkmark$ & $\checkmark$ & $\checkmark$ & $\checkmark$ & $r \mu$ & $1 \leqslant$ & 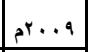 & سامح محمد الجداوى & .14 \\
\hline$\checkmark$ & & & $\checkmark$ & $\checkmark$ & & & $\checkmark$ & & & & $\checkmark$ & $\checkmark$ & $\checkmark$ & $\checkmark$ & $\checkmark$ & $\checkmark$ & & & & $\checkmark$ & $\checkmark$ & & $\checkmark$ & $\checkmark$ & $r \varepsilon$ & rq & ar...9 & محمد عيد زكى & $1 \varepsilon$ \\
\hline \multirow[t]{2}{*}{$\checkmark$} & & & & $\checkmark$ & & & $\checkmark$ & & & & & & & & & & & & & & & & & & $1 \leqslant 1$ & $r$ & \begin{tabular}{|l|l|} 
ar. \\
\end{tabular} & نبيلة أحمد عبد الرحمن وآخرون & .17 \\
\hline & & & $\checkmark$ & $\checkmark$ & $\checkmark$ & & $\checkmark$ & & & & $\checkmark$ & $\checkmark$ & $\checkmark$ & $\checkmark$ & & $\checkmark$ & & $\checkmark$ & $\checkmark$ & $\checkmark$ & $\checkmark$ & $\checkmark$ & $\checkmark$ & $\checkmark$ & $r$. & iv & 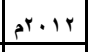 & عبد الرحمن محمود الخياط & $.1 \mathrm{~V}$ \\
\hline \multirow[t]{2}{*}{$\checkmark$} & & & $\checkmark$ & & & $\checkmark$ & & & & & & & & & & & & & & & & & & & $\leqslant \leqslant 4$ & $r \leq$ & 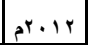 & محمد حسن علاوى & .11 \\
\hline & & & $\checkmark$ & & & & $\checkmark$ & $v$ & & & & $\checkmark$ & $\checkmark$ & $\checkmark$ & $\checkmark$ & $\checkmark$ & & $\checkmark$ & & $\checkmark$ & $\checkmark$ & $\checkmark$ & $\checkmark$ & $\checkmark$ & $r r$ & $r$. & 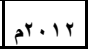 & منى سعد حسين & 19 \\
\hline$\varepsilon$ & 1 & $r$ & ir & $\wedge$ & $\varepsilon$ & r & 1 & $\therefore$ & & & 9 & 1. & 1. & 1. & 1 & $\wedge$ & $r$ & $\mathrm{v}$ & 1 & 9 & 1. & $\wedge$ & 1. & $\wedge$ & \multicolumn{4}{|r|}{ التكرار } & \\
\hline 19 & $r \leq$ & $r$ & 1 & $1 \leqslant$ & $r$ r. & $r r$ & 1 & 1 & & & 1. & $\wedge$ & $\circ$ & $r$ & 17 & ir & $r r$ & 10 & iv & 9 & $\varepsilon$ & $1 r$ & 1 & 11 & \multicolumn{5}{|c|}{ الترتيب } \\
\hline
\end{tabular}


وتفاوتت نسبة الاتفاق المرجعى عليها بشكل كبير، وجاء ترتيبها كما يلى بجدول(؛ ).

\begin{tabular}{|c|c|c|}
\hline النسبة المئوية & المهــارات & م \\
\hline \% & الاستماع الجيد & 1 \\
\hline$\% \circ V$ & استخدام لغة الجسد & r \\
\hline$\%$ or & الاستجابة الانفعالية & r \\
\hline$\% \circ r$ & إدر الك الدور &.$\varepsilon$ \\
\hline$\% \circ r$ & التعامل الإيجابى & .0 \\
\hline$\%$ or & الحضور و اليقظة & .7 \\
\hline$\% \circ r$ & الإنصات الفعال &.$v$ \\
\hline$\%$ or & توجهات الأداء &.$\wedge$ \\
\hline$\% \leqslant V$ & الضبط الانفعالى & .9 \\
\hline$\% \leqslant v$ & توصيل المعلومات & .1 . \\
\hline$\% \leqslant r$ & التفكير & .11 \\
\hline$\% \leqslant r$ & التحدث و الإقناع & $.1 T$ \\
\hline$\% \leqslant r$ & التوقع & r \\
\hline$\% \leqslant r$ & النغمة الصوتية & $.1 \varepsilon$ \\
\hline
\end{tabular}




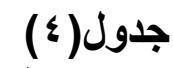

( $19=0$

\begin{tabular}{|c|c|c|}
\hline النسبة المئوية & المهـارات & م \\
\hline$\%$ & استقر ار السلوك & .10 \\
\hline$\%$ \% & فن التعامل مع الآخرين & .17 \\
\hline$\%$ \% & الثقة و التقدير & $.1 \mathrm{~V}$ \\
\hline$\%$ \% & توجيه الأسئلة & .11 \\
\hline$\% r_{1}$ & السلوك اللمسى & .19 \\
\hline$\% r_{1}$ & مكافأة السلوك & r. \\
\hline$\% 10$ & الحوار & r \\
\hline$\% 10$ & ملاحظة السلوك & rr \\
\hline$\% 1$. & التغذية الراجعة & r \\
\hline$\% \circ$ & التفاوض & $. r \leq$ \\
\hline
\end{tabular}

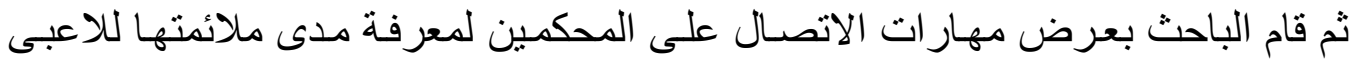

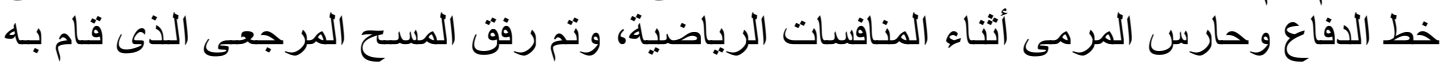

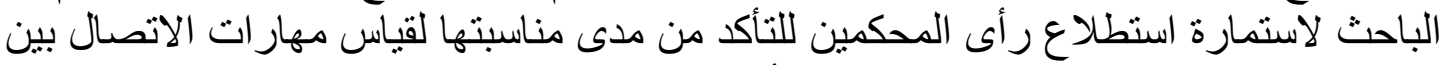

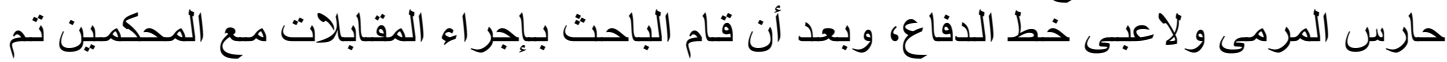

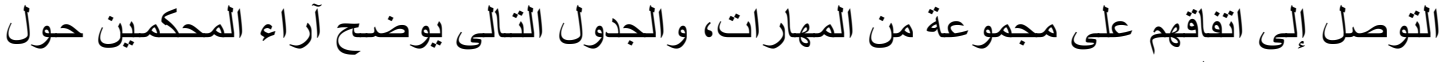

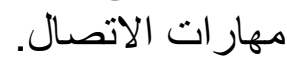




\section{جدول (0)}

رأى المحكمين حول مهارات الاتصال

$(1 \mu=\dot{0})$

\section{مهارات الاتصال}

\begin{tabular}{|c|c|c|c|c|c|c|c|c|c|c|c|c|c|c|c|c|c|c|c|c|c|c|c|c|}
\hline \multirow[t]{8}{*}{ 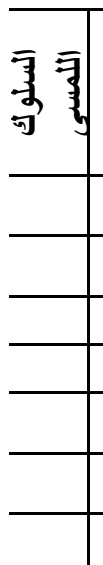 } & $\begin{array}{l}\text { 司 } \\
\text { · }\end{array}$ & $\frac{\overline{3}}{7}$ & 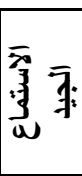 & 浔 & 昰素 & 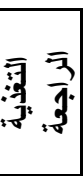 & 羿高 & 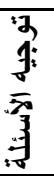 & 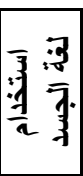 & 3. & 哥哥 & 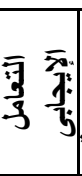 & 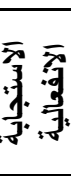 & 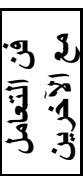 & 可高离 & 各牙 & 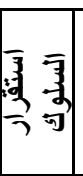 & 氞 & 牙羿 & $\begin{array}{l}\overline{3} \\
\text { ज़ } \\
\overline{3} \\
\text { ज }\end{array}$ & 司 & $\begin{array}{l}\overline{7} \\
3 \\
3 \\
\end{array}$ & 司 & $\overline{3}$ \\
\hline & & $\checkmark$ & $\checkmark$ & & & & $\checkmark$ & $\checkmark$ & $\checkmark$ & $\checkmark$ & & $\checkmark$ & $\checkmark$ & $\checkmark$ & $\checkmark$ & $\checkmark$ & & & $\checkmark$ & $\checkmark$ & $\checkmark$ & $\checkmark$ & $\checkmark$ & 1 \\
\hline & & $\checkmark$ & & $\checkmark$ & & & $\checkmark$ & & $\checkmark$ & $\checkmark$ & & $\checkmark$ & & $\checkmark$ & & & & & $\checkmark$ & $\checkmark$ & $\checkmark$ & $\checkmark$ & $\checkmark$ & $r$ \\
\hline & & & & $\bar{\checkmark}$ & & & $\bar{\checkmark}$ & & $\bar{\checkmark}$ & $\checkmark$ & $\bar{\checkmark}$ & $\bar{\checkmark}$ & & & $\bar{\checkmark}$ & & & & $\bar{\checkmark}$ & $\checkmark$ & $\bar{\checkmark}$ & $\checkmark$ & $\checkmark$ & $r$ \\
\hline & $\checkmark$ & & & $\checkmark$ & $\bar{\checkmark}$ & & $\checkmark$ & & $\checkmark$ & $\checkmark$ & & $\checkmark$ & $\checkmark$ & & $\checkmark$ & & & $\checkmark$ & & $\checkmark$ & $\checkmark$ & $\checkmark$ & $\checkmark$ & $\varepsilon$ \\
\hline & $\checkmark$ & & $\checkmark$ & $\checkmark$ & & & $\checkmark$ & $\checkmark$ & $\checkmark$ & $\checkmark$ & & $\checkmark$ & & & $\checkmark$ & $\checkmark$ & & & & $\checkmark$ & $\checkmark$ & $\checkmark$ & & 0 \\
\hline & & & & $\checkmark$ & & & & & $\checkmark$ & & $\checkmark$ & $\checkmark$ & & & $\checkmark$ & $\checkmark$ & $\checkmark$ & & & $\checkmark$ & $\checkmark$ & $\checkmark$ & & 7 \\
\hline & & & $\checkmark$ & $\checkmark$ & & & $\checkmark$ & $\checkmark$ & $\checkmark$ & & & $\checkmark$ & $\checkmark$ & & $\checkmark$ & & $\checkmark$ & & & $\checkmark$ & $\checkmark$ & $\checkmark$ & & $v$ \\
\hline$\checkmark$ & & $\checkmark$ & $\checkmark$ & & $\checkmark$ & & $\checkmark$ & $\checkmark$ & $\checkmark$ & & & $\checkmark$ & $\checkmark$ & $\checkmark$ & $\checkmark$ & & & & $\checkmark$ & $\checkmark$ & $\checkmark$ & $\checkmark$ & $\checkmark$ & $\Lambda$ \\
\hline$\checkmark$ & & $\checkmark$ & $\checkmark$ & $\checkmark$ & & & $\checkmark$ & $\checkmark$ & $\checkmark$ & & $\checkmark$ & $\checkmark$ & & & $\checkmark$ & & & & & $\checkmark$ & $\checkmark$ & $\checkmark$ & & 9 \\
\hline$\checkmark$ & & & & $\checkmark$ & & & $\checkmark$ & & $\checkmark$ & $\checkmark$ & & $\checkmark$ & $\checkmark$ & $\checkmark$ & $\checkmark$ & & & $\checkmark$ & $\checkmark$ & $\checkmark$ & $\checkmark$ & $\checkmark$ & $\checkmark$ & 1. \\
\hline$\checkmark$ & $\checkmark$ & & & $\checkmark$ & & $\checkmark$ & $\checkmark$ & & $\checkmark$ & $\checkmark$ & $\checkmark$ & $\checkmark$ & & & $\checkmark$ & & & & & & $\checkmark$ & $\checkmark$ & & 11 \\
\hline \multirow[t]{2}{*}{$\checkmark$} & & & & $\checkmark$ & & & $\checkmark$ & $\checkmark$ & $\checkmark$ & & $\checkmark$ & $\checkmark$ & & $\checkmark$ & & & $\bar{\checkmark}$ & & & $\checkmark$ & $\checkmark$ & $\checkmark$ & & Ir \\
\hline & & $\checkmark$ & & & & & $\checkmark$ & & $\checkmark$ & & & $\checkmark$ & $\checkmark$ & & $\checkmark$ & $\checkmark$ & & & $\checkmark$ & $\checkmark$ & $\checkmark$ & $\checkmark$ & $\checkmark$ & ir \\
\hline 0 & $r$ & 0 & 0 & 1. & $r$ & 1 & Ir & 9 & ir & $V$ & 0 & 14 & 7 & 0 & 11 & $\varepsilon$ & $r$ & $r$ & 7 & ir & 14 & 14 & $\mathrm{~V}$ & التكرار \\
\hline IV & $r 1$ & $1 \varepsilon$ & 11 & $\wedge$ & rr & $Y \varepsilon$ & 7 & $1 \pi$ & r & 9 & 10 & $r$ & Ir & 17 & $v$ & 19 & r. & rr & 11 & 0 & $\varepsilon$ & 1 & 1. & الترتيب \\
\hline
\end{tabular}

بدراسة جدول(0)، يتبين: أن نسبة اتفاق المحكين لمهار ات الاتصال جاء ترتيبها كما يلى بجدول(؟). 


\begin{tabular}{|c|c|c|}
\hline النسبة المئوية & المهــــــات & 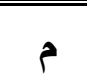 \\
\hline$\%$ & الحضور واليقظة & $\overline{.1}$ \\
\hline$\% 1 \ldots$ & استخذام لغة الجسد &. $\bar{T}$ \\
\hline$\% 1 \ldots$ & التعامل الايجابى & $r$ \\
\hline$\% 1 \ldots$ & التوقع &.$\varepsilon$ \\
\hline$\% 94$ & إدراك الدور & .0 \\
\hline$\% 94$ & الإنصات الفعال & .7 \\
\hline$\% \wedge \varepsilon$ & التحدث والإقناع &.$V$ \\
\hline$\% \vee 4$ & النغمة الصوتية &.$\wedge$ \\
\hline$\%$ or & توصيل المعلومات & .9 \\
\hline$\%$ or & التفكير & .1. \\
\hline$\% \leqslant 7$ & الضبط الانفعالى & .11 \\
\hline$\% \leqslant 7$ & الاستجابة الانفعالية & .14 \\
\hline$\% \leqslant 7$ & توجية الأسئلة & .14 \\
\hline$\% \%^{r \Lambda}$ & الحوار & $.1 \varepsilon$ \\
\hline$\%$ \% & توجهات الأداء & .10 \\
\hline$\%$ \%ऑ & فن التعامل مع الآخرين & .17 \\
\hline$\%$ \%r & السلوك اللمسى & $.1 \mathrm{~V}$ \\
\hline$\%$ \% & الاستماع الجيد & .11 \\
\hline$\% r$. & ملاحظة السلوك & .19 \\
\hline$\%$ \% & استقرار السلوك &.$r$. \\
\hline$\%$ \% & التفاوض &.$T$ \\
\hline$\% 10$ & مكأفاة السلوك & .YY \\
\hline$\% 10$ & الثقة والتقدير & $\mathrm{ST}^{\mathrm{T}}$ \\
\hline$\%{ }^{\mathrm{v}}$ & التغذية الراجعة &.$T \xi$ \\
\hline
\end{tabular}

\section{جدول (") \\ النسبة المئوية لمهارات الاتصال وفقًا لآراء المحكمين}




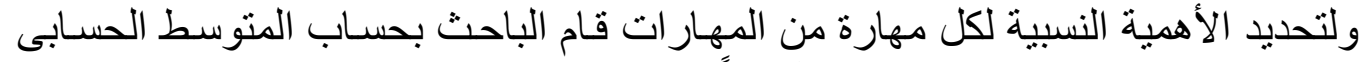

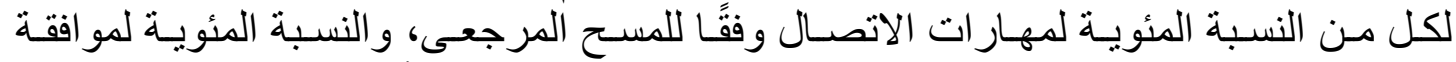

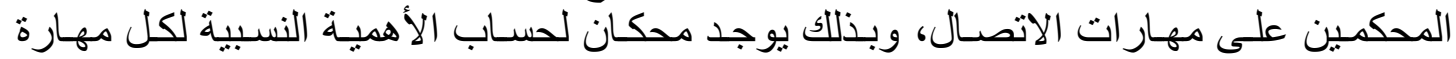

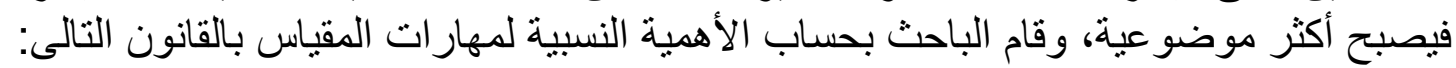
الأهمية النسبية للمهارة = النسبة المئوية للمهارة وفقًا للمسح المرجعى + النسبة المئوية للمهارة وفقًا لآراء المحكمين

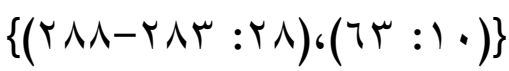

وفيما يلى جدول(V)، و الذى يبين الأهمية النسبية لمهارات الاتصال.

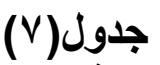

الأهمية النسبية لمهارات الاتصال

\begin{tabular}{|c|c|c|c|c|}
\hline \multirow{2}{*}{ الأهمية النسبية } & \multicolumn{2}{|c|}{ النسبة المئوية } & \multirow{2}{*}{ المهارات } & \multirow{2}{*}{ p } \\
\hline & وفقا لآراء المحكمين & وفقا للمسح المرجعى & & \\
\hline$\% \vee \wedge$ & $\% 1$. & $\% \circ V$ & استخدام لغة الجسد & .1 \\
\hline$\% \vee 7$ & $\% 1 \ldots$ & $\%$ OY & الحضور و اليقظة &.$Y$ \\
\hline$\% \vee 7$ & $\% 1 \ldots$ & $\% \circ r$ & التعامل الايجابى &.$r$ \\
\hline$\% \vee Y$ & $\% 94$ & $\% \circ Y$ & إدر الك الدور &.$\varepsilon$ \\
\hline$\% \vee Y$ & $\% 9 r$ & $\% \circ r$ & الإنصات الفعال & .0 \\
\hline$\% \vee 1$ & $\% 1 \ldots$ & $\% \leqslant r$ & التوقع & .7 \\
\hline$\% \pi r$ & $\% \wedge \varepsilon$ & $\% \leqslant r$ & التحدث و الإقناع &.$V$ \\
\hline$\% 09$ & $\% \vee 7$ & $\% \leqslant r$ & النغمة الصوتية &.$\wedge$ \\
\hline
\end{tabular}

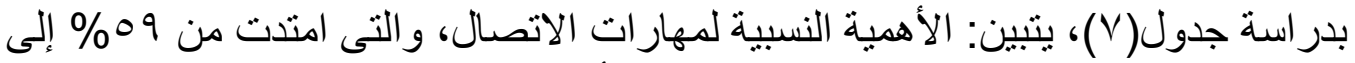

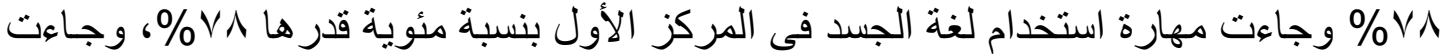

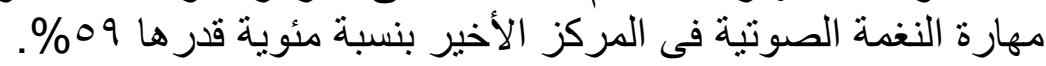

㳊

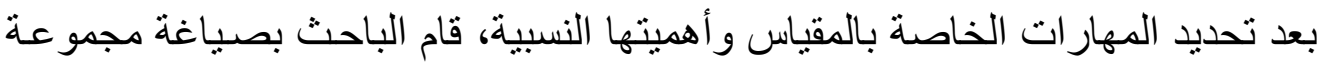

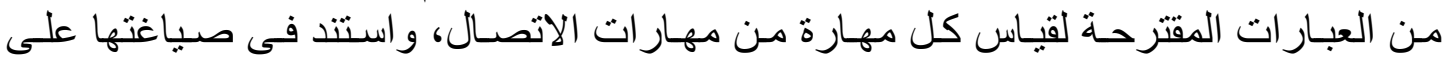

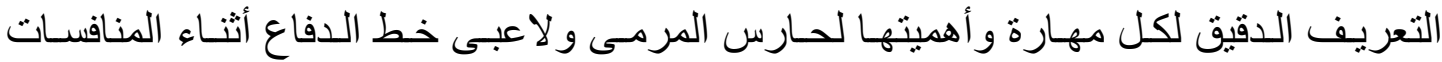

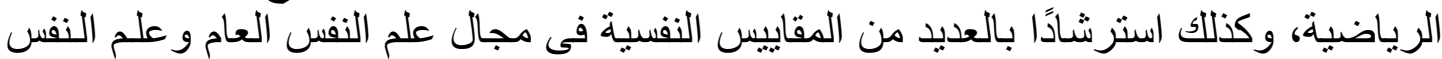

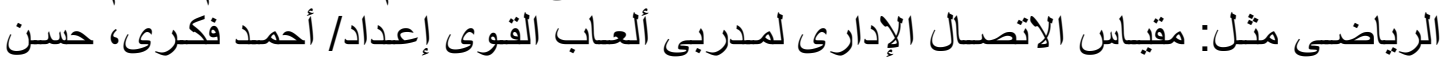




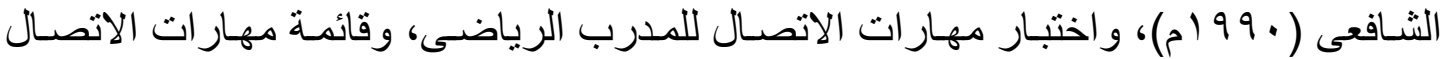

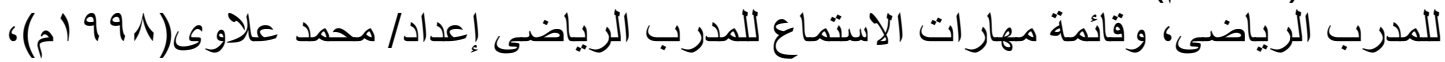

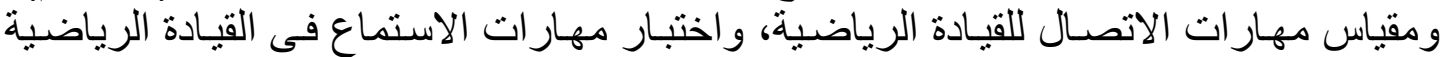

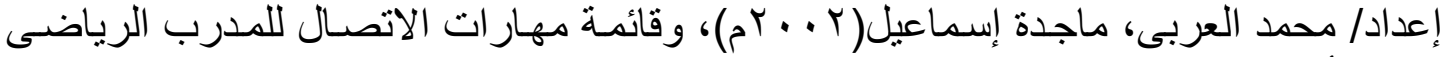

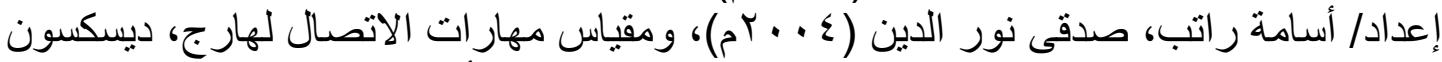
Hargie, Dickson

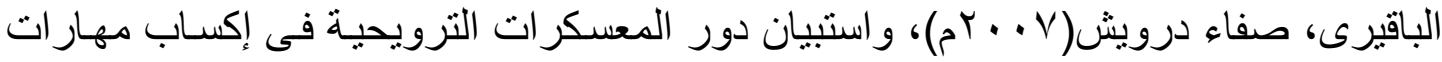

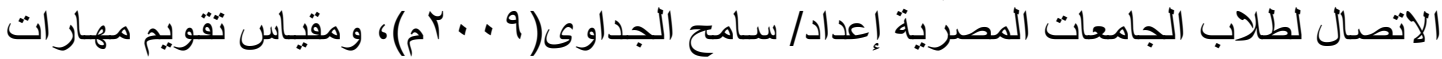

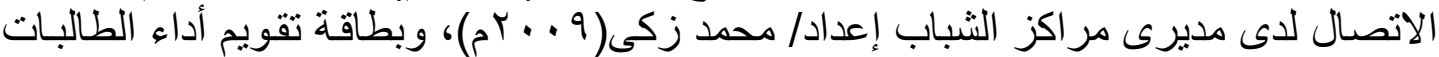

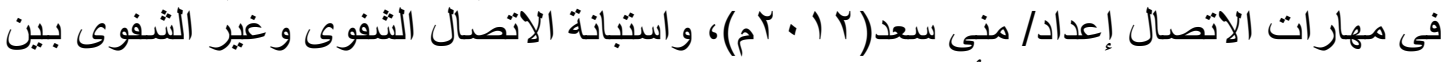

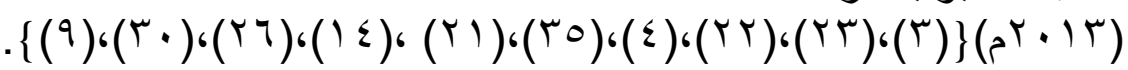

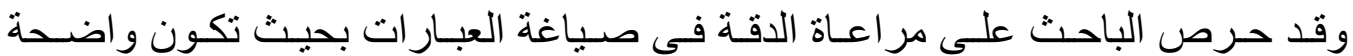

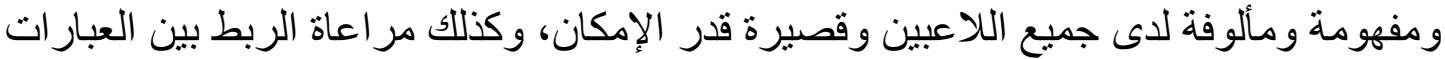

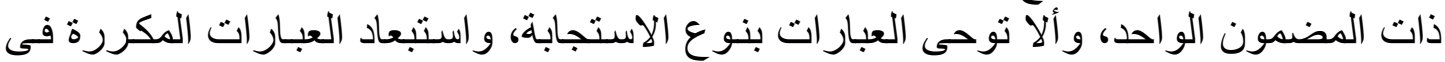

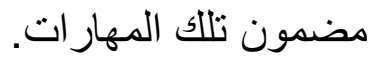

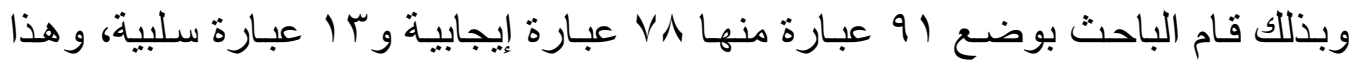

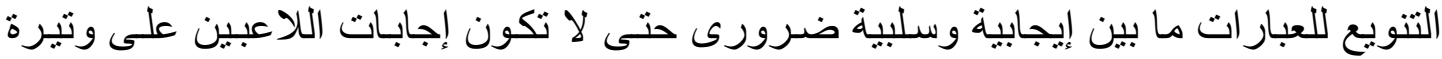

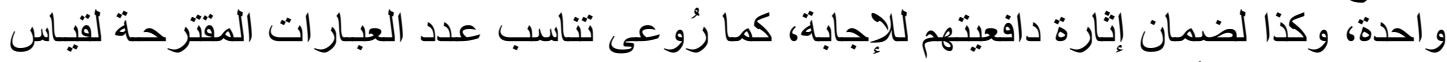
كل مهارة مع الأهمية النسبية لهان.

و الجدول التـالى يُبين مجموع العبـار ات الإيجابيـة والسلبية المقترحـة لمقيـاس مهار ات الاتصال بين حارس المرمى و لاعبى خط الدفاع. 
جدول (^)

مجموع العبارات الإيجابية والسلبية المقترحة لمقياس مهارات الاتصال

\begin{tabular}{|c|c|c|c|c|}
\hline \multirow{2}{*}{ مجموع العبارات } & \multicolumn{2}{|c|}{ عدد العبارات المقترحة } & \multirow{2}{*}{ مهارات الاتصال } & \multirow{2}{*}{ b } \\
\hline & السلبية & الإيجابية & & \\
\hline 17 & - & 17 & استخدام لغة الجسد & .1 \\
\hline 10 & $r$ & IT & الحضور و اليقظة &.$Y$ \\
\hline $1 \varepsilon$ & $\mu$ & 11 & التعامل الايجابى & r \\
\hline IT & $r$ & 1. & إدر الك الدور & $\varepsilon$ \\
\hline 11 & r & 9 & الإنصات الفعال & 0 \\
\hline 1. & 1 & 9 & التوقع & .7 \\
\hline$\Lambda$ & r & 7 & التحدث و الإقناع &.$V$ \\
\hline 0 & - & 0 & النغمة الصوتية &.$\wedge$ \\
\hline 91 & 14 & VA & لمحموع & \\
\hline
\end{tabular}

الاولة/

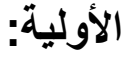

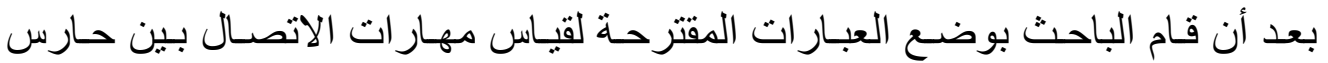

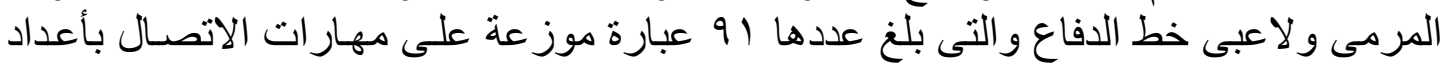

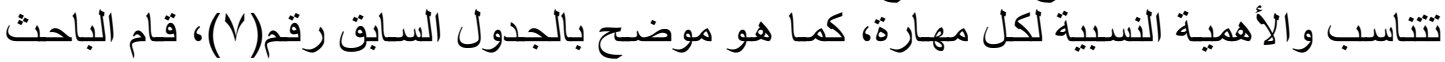

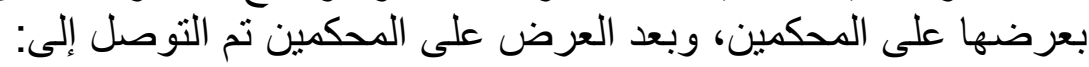

- - الاتفاق على (آ عبارة من عبار ات المقياس بعد إعادة صياغتها لغويًا من قبل

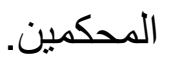

- إضافة 10 عبارة جديدة كما هو موضح بجدول(9). - حذف • م عبارة من عبارات المقياس وأرقامهم كما هو موضح بجدول( • ( ). 
جاول (9)

العبارات التى تم إضافتها لمهارات الاتصال وفقًا لآراء المحكمين العبارات التى تم إضافتها

المهارة

\begin{tabular}{|c|c|}
\hline العبارات التى تم إضافتها & المهارة \\
\hline أجد صعوبة فى عمل حائط صد جيد فى تتفيذ الركلات الثابتة ضد فريقى. & \multirow{4}{*}{$\begin{array}{l}\overline{3} \\
\text { ज̄ } \\
\text { 亏 }\end{array}$} \\
\hline دفاع ناجح ضد أى كرة مضروبة تجاهى. & \\
\hline قوى. أستمتع بتحمل أيـة مهمـة والتى برى زملائسى المدافعين أنها مهمـة صـعبة كمر اقبـة منـافس & \\
\hline أستطيع أن أدافع عن مرمانا مهما كان المنافس قوياً. & \\
\hline أتعاون إيجابياً مع اللاعبين المصابين وأطمأن عليهم عندما يقعون على الأرض. & 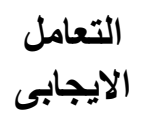 \\
\hline ل المدافع بقولى(حافظ عليها) للتعبير عن الاحتفاظ بالكرة حتى بأتى زميل & \multirow{9}{*}{ 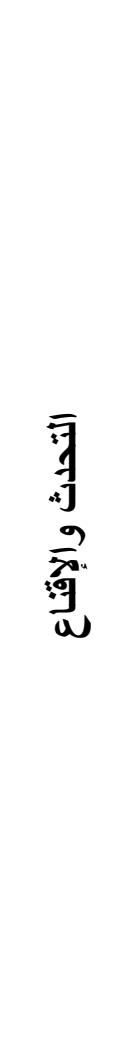 } \\
\hline زملائى المدافعين بقولى(ر اقب) لتنبيه اللاعبين على مر اقبة اللاعبين المنافسين. & \\
\hline زميلى المدافع بقولى(اسند) لمساعدة الزميل الحائز على الكرة ومساندته. & \\
\hline تنادى على زميلك المدافع بقولك(بر ا) لإخر اج الكرة خارج الملعب. & \\
\hline دفادى على زأفضل منله المدافع بقولك(سيبها) أو تقول اسمك لترك الكرة للك لأنك فى موقف & \\
\hline أنـادى على زميلى المدافع بقولى(غير الملعب) للتعبير عن التمريـر الطويل لتغيير جهة & \\
\hline أنادى على زميلى المدافع بقولى(مرر) للتعبير عن تمرير الكرة للزملاء. & \\
\hline أنادى على زملانى المدافعين بقولى(اطلع) للتعبير عن كثف منطقة التسلل للفريق. & \\
\hline الكرةد. على زميلى المدافع بقولى(اضغط) للتعبير عن الضغط على المنـافس المستحوذ على & \\
\hline 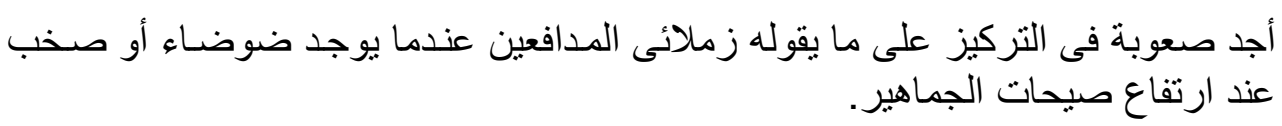 & الإنصال \\
\hline
\end{tabular}




\begin{tabular}{|c|c|}
\hline أرقام العبارات & المهارة \\
\hline $10-V-\varepsilon-1$ & استخدام لغة الجسد \\
\hline$\left|\varepsilon_{-}\right| r_{-}\left|Y_{-}\right| 1-V_{-} \tau_{-} \varepsilon$ & الحضور و اليقظة \\
\hline $1 T_{-}\left|Y_{-}\right| \cdot-\Lambda_{-} \theta_{-} \varepsilon$ & التعامل الايجابى \\
\hline 1 . & إدر الك الدور \\
\hline $11-1 \cdot-9-1-V_{-}-T_{-} r$ & الإنصات الفعال \\
\hline q_o_rn-1 & التوقع \\
\hline$r$ & التحدث و الإقناع \\
\hline- & النغمة الصوتية \\
\hline
\end{tabular}

إن/ / / / / / / / مقياس مهارات الاتصال بين حارس المرمى ولاعبى خط الدفاع فى صورته

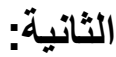

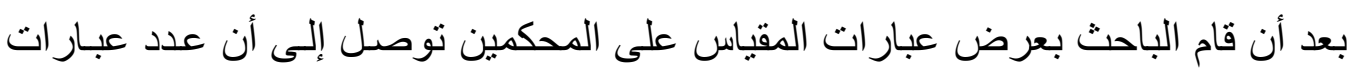

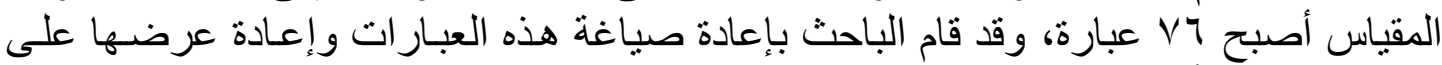

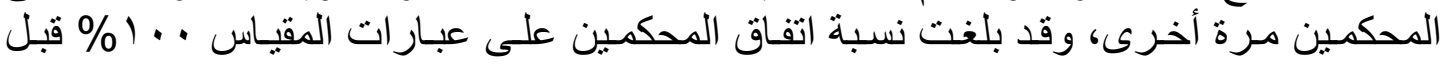
إجر اء المعاملات السيكومنرية.

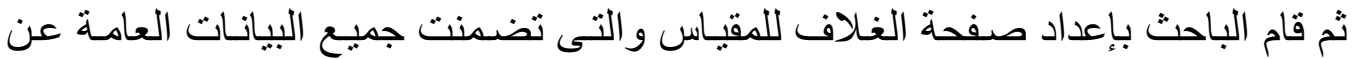

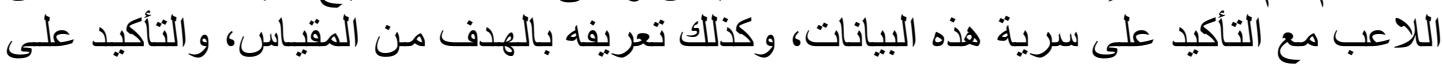

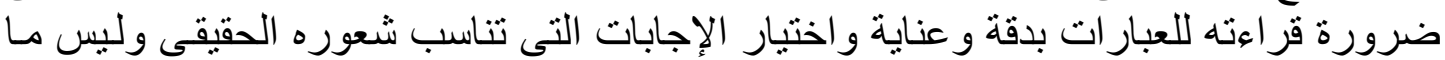

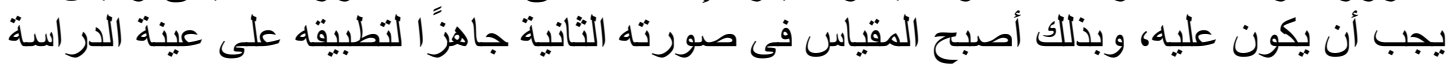
الاستطلاعية لحساب المعاملات السيكومترية له له

خطاع/ / / / / / / / المعاملات السيكومترية لمقياس مهارات الاتصال بين حارس المرمى ولاعبى

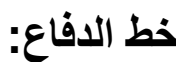
Validity

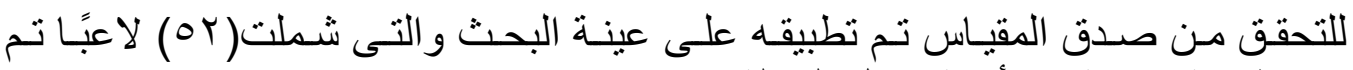

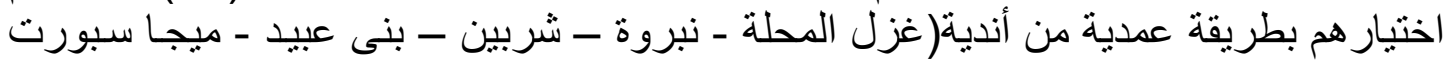

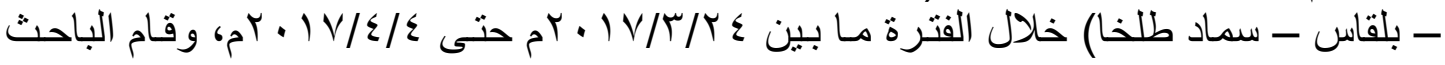

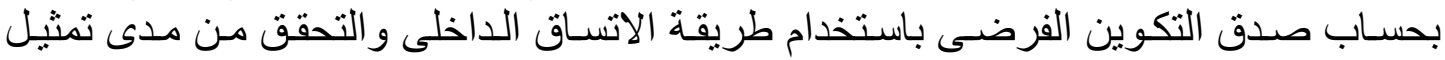

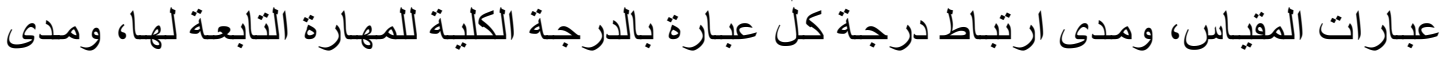
ارتباط درجات مهار ات المقياس فيما بينها و الدرجة الكلية للمقياس. 
جدول(1)

مصفوفة الارتباطات البينية بين العبارة والدرجة الكلية للمهارة

(or $=\dot{0})$

\begin{tabular}{|c|c|c|c|c|c|c|c|c|c|c|c|}
\hline \multicolumn{2}{|c|}{ الإنصات الفعال } & \multicolumn{2}{|c|}{ استخدام لغة الجسد } & \multicolumn{2}{|c|}{ التعامل الايجابى } & \multicolumn{2}{|c|}{ التحدث والإقناع } & \multicolumn{2}{|c|}{ إدراك الدور } & \multicolumn{2}{|c|}{ الحضور واليقظة } \\
\hline J & العبارة & J & العبارة & J & العبارة & J & العبارة & J & |العبارة & J & العبارة \\
\hline$* * ., T r K$ & 1 & $\cdot, Y \cdot T$ & 1 & $\cdot, 1 \leq 7$ & 1 & $* *, V \cdot V$ & 1 & $\cdot, \cdots$ & 1 & $*_{.}$, Y人T & 1 \\
\hline$* *,, \vee 9 r$ & $r$ & $* *$, , $\{\uparrow \wedge$ & $r$ & $\cdot, \cdot 9 \cdot-$ & r & $* *,, \vee 10$ & $r$ & $* *,, \varepsilon \wedge \varepsilon$ & r & $\cdot, Y O \Lambda$ & r \\
\hline$\cdot, r \leqslant Y$ & $r$ & 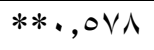 & $r$ & $* *, 711$ & $r$ & **, , T1. & $r$ & •, YYq & $r$ & $* *, 09$ & $r$ \\
\hline$* * ., T V T$ & $\varepsilon$ & $\cdot, 1 \cdot \varepsilon_{-}$ & $\varepsilon$ & $* *, 79 V$ & $\varepsilon$ & $* *, 0 \leqslant \Lambda$ & $\varepsilon$ & $\cdot, Y 01$ & $\varepsilon$ & $* *,, \vee \wedge \wedge$ & $\varepsilon$ \\
\hline$* * ., \leq 9 \wedge$ & 0 & $* *, 001$ & 0 & **., เ V & 0 & $* *_{.}, \leq \leq$. & 0 & $\cdot, 1 \vee 4$ & 0 & $\cdot,|Y|{ }_{-}$ & 0 \\
\hline \multicolumn{2}{|c|}{ النغمة الصوتية } & $\cdot, 194$ & 7 & $\cdot, r Y q_{-}$ & 7 & $* * ., 0 V V$ & 7 & $* *,\{Y)$ & 7 & $* *,, \Sigma \vee \wedge$ & 7 \\
\hline J & العبارة & $* *,, Y Y$. & V & $* * ., \Sigma 71$ & V & $* * ., 009$ & V & $* *$, , $2 \wedge \vee$ & V & **, , זчr & V \\
\hline$* * ., 7 Y \leq$ & 1 & $\cdot, I A Y$ & $\wedge$ & $\cdot, \mid \vee \varepsilon$ & $\wedge$ & $* * ., T \vee \varepsilon$ & $\wedge$ & $\cdot, Y Y Y$ & $\wedge$ & $* * ., 0 Y$. & $\wedge$ \\
\hline$* *$, , TV^ & r & $* *$, , $\{\wedge$ & 9 & $* *$. Ћү9 & 9 & $\cdot, 117$ & 9 & $* *, 7,1$ & 9 & \multicolumn{2}{|c|}{ التوقع } \\
\hline$* * \cdot, \wedge \leq \uparrow$ & r & $\cdot, Y \backslash 1$ & 1. & & & **., ס & 1. & *., TOY & 1. & J & العبارة \\
\hline$* * ., 019$ & $\varepsilon$ & $* *,, \vee \backslash r$ & 11 & & & $* *$, , ๆ. 0 & 11 & $* *$, , & 11 & $\cdot, 191$ & 1 \\
\hline \multirow[t]{5}{*}{ **., 771} & 0 & $* *,, \vee \vee 0$ & IT & & & $* *,, \Sigma \wedge r$ & IT & $* *,, \Sigma \varepsilon r$ & Ir & $* *,, \backslash \leq \varepsilon$ & $r$ \\
\hline & & & & & & **., ०น 9 & $1 \pi$ & $* * ., \leq 0 ૫$ & $1 \pi$ & ., . & $r$ \\
\hline & & & & & & $\cdot, \cdot \wedge$. & $1 \leq$ & $* *, 711$ & $1 \varepsilon$ & $*_{., Y \wedge 9}$ & $\varepsilon$ \\
\hline & & & & & & $* * ., \Sigma 9 r$ & 10 & $\cdot, \mid \vee \wedge$ & 10 & $* * ., 07 \varepsilon$ & 0 \\
\hline & & & & & & *., . & 17 & & & $* * ., 0 \wedge \Gamma$ & 7 \\
\hline
\end{tabular}

بدر اسة جدول (1) (1) يتبين: وجود ارتباط ذو دلالة إحصائية بين العبارة و الدرجة الكلية

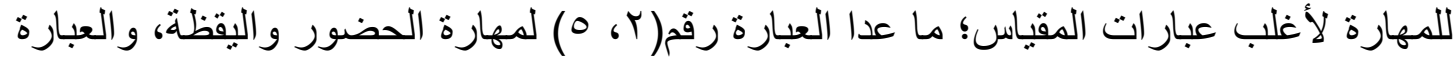

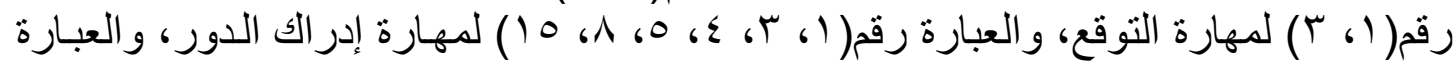

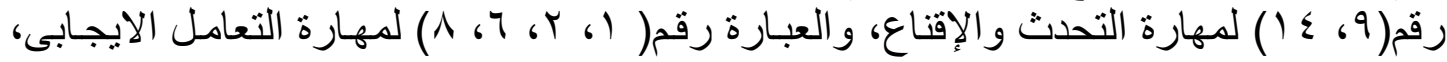

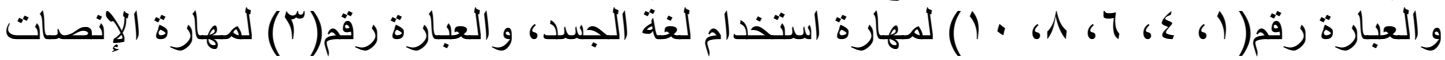
الفعال، وقد قام الباحث باستبعاد هذه العبار ات من المقارة المقاس. 


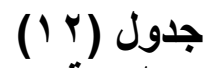

مصفوفة الارتباطات البينية بين مهارات الاتصال

(Or = (ن)

\begin{tabular}{|c|c|c|c|c|c|c|c|c|c|}
\hline الصوتية & الإنصال & الجسدام لغة & الايجابى & والإقتاع & الدراك & التوقع & واليقظة & المهارات & p \\
\hline$* *, \leqslant 1 \wedge$ & $\begin{array}{c}- \\
* *, \xi Y \mu\end{array}$ & $* *, r \wedge \varepsilon_{-}$ & $* *,, 0 \leqslant 0$ & $* *$, , $\leqslant$ r & $\begin{array}{c}*, \text {, irq } \\
*\end{array}$ & $\begin{array}{c}*_{,}, \varepsilon V V \\
*\end{array}$ & & ليقظة الحضورا & 1 \\
\hline$* *, \wedge ৭$ & $* *, 041$ & $* *,,\{\wedge 0$ & $* *, 0 \leqslant$ & $* *, 01$. & $\begin{array}{c}*_{.}, 0 \leqslant 0 \\
*\end{array}$ & & & التوقع & r \\
\hline$* *, \leqslant \circ V$ & $* *$, , O Y & $* * *_{0}, \varepsilon \vee \varepsilon_{-}$ & $* *,, v 11$ & $* *, \ldots 4$. & & & & إلدراك & $r$ \\
\hline$* *, 0, r_{-}$ & $\begin{array}{c}- \\
* * ., \leqslant \vee 0\end{array}$ & $* *,$, , & $* * ., \leq 44$ & & & & & والتحنداع & $\varepsilon$ \\
\hline$* *, 449$ & $\begin{array}{l}- \\
* *, \text { rqq }\end{array}$ & $* *, 07 \%$ & & & & & & الايجابى & 0 \\
\hline$* * \cdot, \varepsilon \wedge 0$ & $\begin{array}{c} \\
* *, \leqslant 1 \%\end{array}$ & & & & & & & لغة الجسدام & 9 \\
\hline$* *, \varepsilon r \cdot-$ & & & & & & & & الإنصات & $\mathrm{v}$ \\
\hline & & & & & & & & الصوتية & $\Lambda$ \\
\hline
\end{tabular}

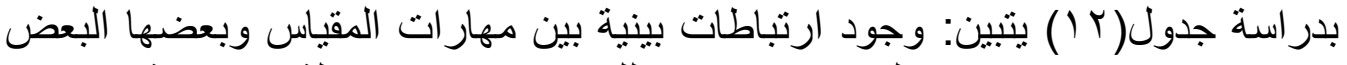

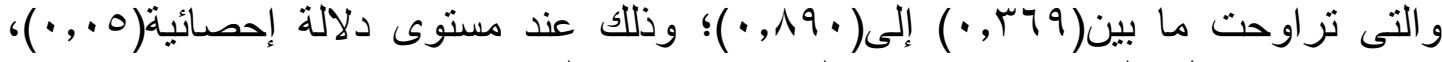
( ( +, •)، مما يذل على وجود اتساق داخلى بين مهار ات ات المقياس. 


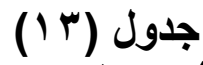

$(\circ r=\dot{0})$

مصفوفة الارتباطات البينية بين المهارات و الدرجة الكلية للمقياس

\begin{tabular}{|c|c|c|}
\hline المقياس & المهارات & م \\
\hline$* * ., \varepsilon r \leqslant$ & الحضور و اليقظة & 1 \\
\hline$* *,, \vee \backslash 1$ & التوقع & r \\
\hline$* *_{\cdot}, \leqslant \vee$. & إدر الك الدور & r \\
\hline$* * ., \leq \leq 9$ & التحدث و الإقناع & $\varepsilon$ \\
\hline$* * ., 0.1$ & التعامل الايجابى & o \\
\hline$* * ., 01$ & استخدام لغة الجسد & 7 \\
\hline **.,orl- & الإنصات الفعال & $\checkmark$ \\
\hline$* * ., 794$ & النغمة الصوتية & $\wedge$ \\
\hline
\end{tabular}

بدراسة جدول(r ا) يتبين: وجود ارتباط ذو دلالة إحصائية بين الدرجة الكلية للمهارة

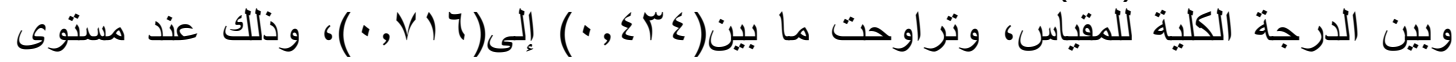

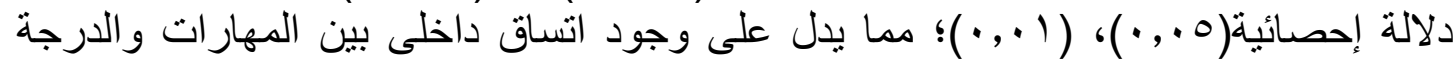

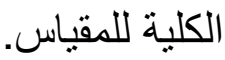

Reliability $r / \bullet / r / 1 / 0 / \mathrm{V} / 1$

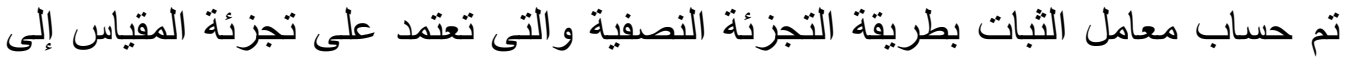

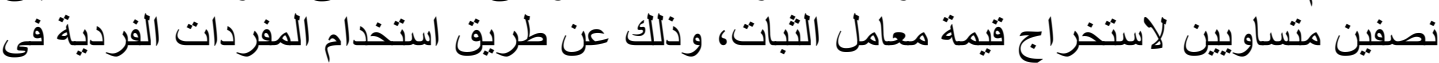

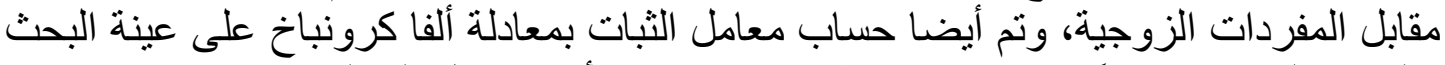

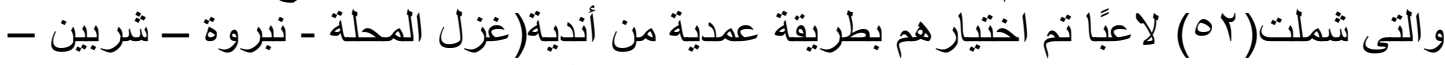

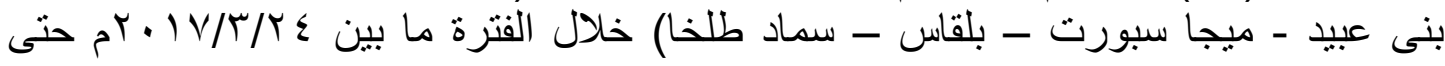
. $r+1 V / \varepsilon / \varepsilon$ 


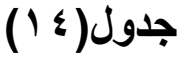

$(0 r=\dot{0})$

\begin{tabular}{|c|c|c|c|c|c|c|c|c|c|}
\hline \multirow{2}{*}{ كرونباخ } & \multirow{2}{*}{ جتمان } & \multirow{2}{*}{ سبيرمان } & \multirow{2}{*}{ الارتباط معامل } & \multicolumn{2}{|c|}{ العبارات الزوجية } & \multicolumn{2}{|c|}{ العبارات الفردية } & \multirow{2}{*}{ المهارات } & \multirow{2}{*}{ r } \\
\hline & & & & $\varepsilon \pm$ & س س & $\varepsilon \pm$ & س س & & \\
\hline., 000 &., $09 V$ & . & $* * ., \varepsilon \leqslant r$ & $1, \varepsilon \cdot r$ & $1 \%, 941$ & $1, \wedge r q$ & Ir,TIY & الحضور واليقظة & 1 \\
\hline., 0.1 & $\cdot, \wedge ч \varepsilon$ & צ & $* *$, , Vฯ & דצד 1, & $V, 04 r$ & $\cdot, Y \otimes D$ & $v, I \wedge v$ & التوقع & $r$ \\
\hline$\cdot, \Delta \vee \leqslant$ & . & $\cdot, \imath \wedge \vee$ & $* *$, , $\$ 17$ & $1,7 \vee \varepsilon$ & $1 \cdot, r \mid r$ & $1, r \leq r$ & & إدراك الدور & $r$ \\
\hline .,ATI & $\cdot, \wedge r \wedge$ & $\cdot, \wedge \leq 1$ & $* *$, VY 0 & T,YMT & $r 0,9,7$ & ש & rA,OTr & التحدث والإقناع & $\varepsilon$ \\
\hline$\cdot, r \cdot r$ & $\cdot, \varepsilon \wedge \vee$ & $\cdot,\{\wedge \wedge$ & $* * ., \varepsilon r \mu$ & $1, r \Delta 0$ & $\wedge, 94 \wedge$ & $1, \& 7 V$ & $9,9.7$ & التعامل الايجابى & 0 \\
\hline$\cdot, \wedge \leq \leq$ & $\cdot, \vee \vee 70$ & $\cdot$, VTV & **, , , & $r, r \leqslant \Lambda$ & $|r, \cdot r|$ & $Y, 09 q$ & $|r, r| A$ & استخدام لغة الجسد & 7 \\
\hline$\cdot, 0 . r$ & $\cdot, \leqslant q \wedge$ & $\cdot, \leqslant q r$ & $* *$, . $\leqslant$ ○r & 1,var & V,or. & D & $\Lambda, r \leq r$ & الإنصات الفعال & $v$ \\
\hline ודיותי &., 079 & .,orr & **,oro & Y,YVT & $9, .94$ & $1, r M A$ & $q, r \leq r$ & النغمة الصوتية & $\wedge$ \\
\hline$\cdot, v \circ r$ & $\cdot, \neg \wedge \varepsilon$ & $\cdot, 79 \varepsilon$ & **, I & V,rr. & $\wedge \wedge, \ldots$ & ד,หד & $৭ \wedge, \wedge \vee \diamond$ & باس مهارات الاتصال & \\
\hline
\end{tabular}

بدر اسة جدول ( ( ) ) يتبين: وجود ارتباط ذو دلالة إحصائية عند مستوى دلالة إحصائية

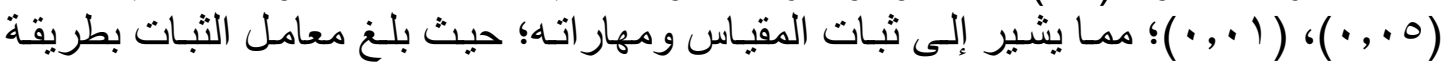

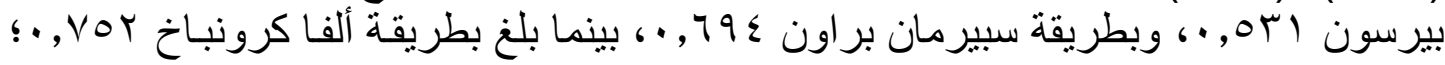
مما يشير إلى ارتفاع معامل ثبات المقياس.



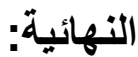

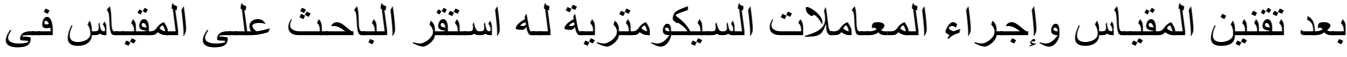

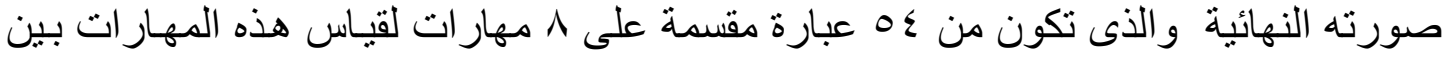

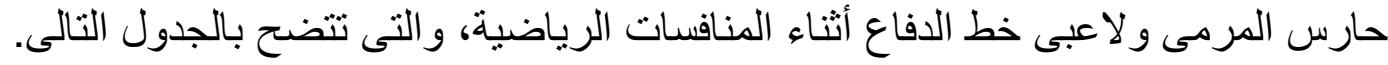


جدول (10)

مجموع وأرقام العبارات الإيجابية و السلبية لمقياس مهارات الاتصال في صورته النهائية

\begin{tabular}{|c|c|c|c|c|}
\hline \multirow{2}{*}{ المجموع } & \multicolumn{2}{|r|}{ أرقام العبارات } & \multirow{2}{*}{ مهارات الاتصال } & \multirow{2}{*}{ b } \\
\hline & السلبية & الايجابية & & \\
\hline 7 & - & $\left.\sum Y_{-} r_{-}-Y_{-}\left|V_{-}\right| Y_{-}\right)$ & الحضور و اليقظة & 1 \\
\hline$\varepsilon$ & 9 & $\sum \Lambda_{-} Y \leqslant-10$ & التوقع & $r$ \\
\hline 9 & $0 .-11-7$ & $\left.\sum T-r V-r T-Y \theta_{-}\right) \cdot-r$ & إدر الك الدور & $r$ \\
\hline $1 \leq$ & \& & 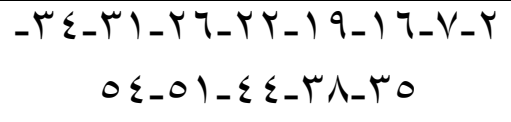 & التحدث و الإقناع & $\varepsilon$ \\
\hline 0 & - & Or-\{0-\&Y-rT-YT & التعامل الايجابى & 0 \\
\hline $\mathrm{v}$ & - & $\sum V_{-} r q_{-}-q_{-}-r V_{-} r \cdot-11-0$ & استخدام لغة الجسد & 7 \\
\hline$\varepsilon$ & YI & $M M_{-} \Lambda_{-} \varepsilon$ & الإنصات الفعال & V \\
\hline 0 & - & $\left.O Y_{-} \varepsilon q-\varepsilon \cdot-Y Y_{-}\right) \varepsilon$ & النغمة الصوتية & $\Lambda$ \\
\hline $0 \leqslant$ & 7 & $\leqslant \wedge$ & $\Lambda$ & المجموع المعل \\
\hline
\end{tabular}

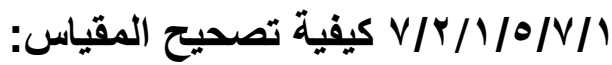

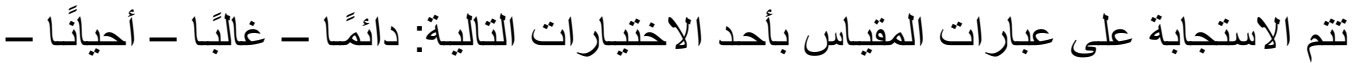

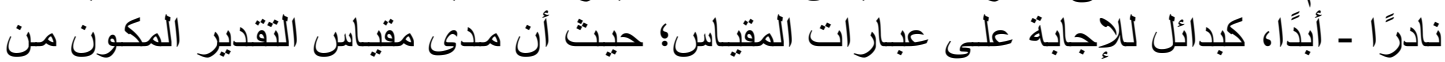

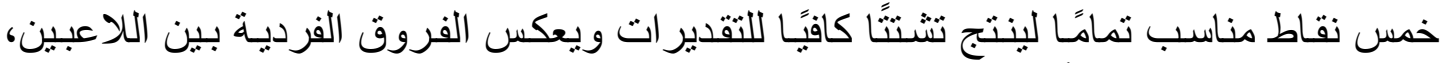
وذللك بهدف التمييز بين أفراد العينة.

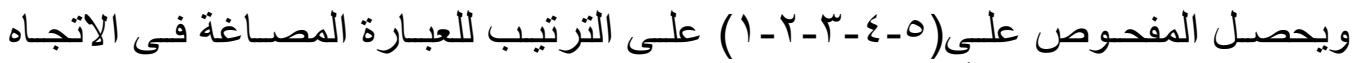

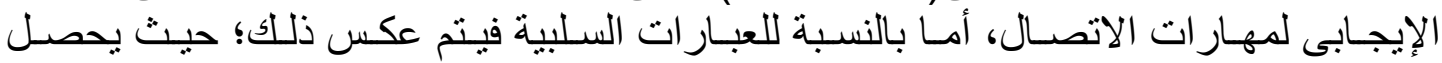

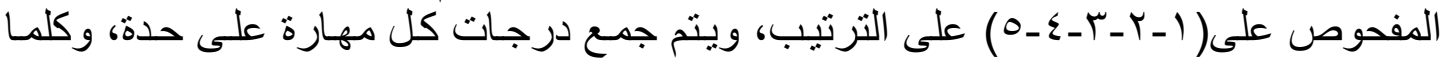

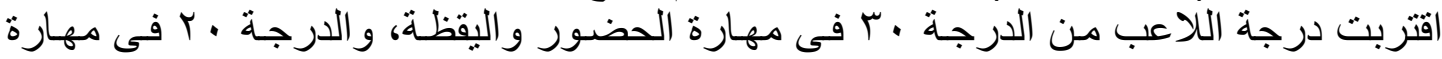

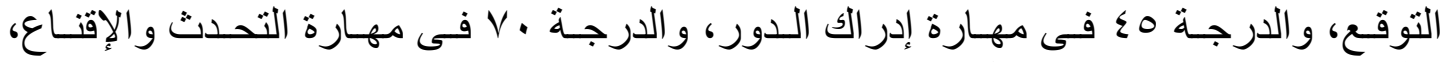

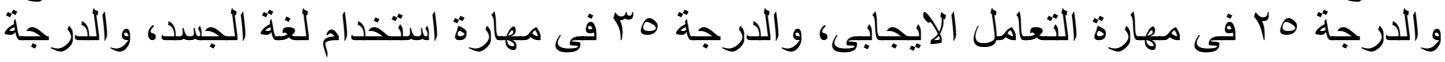

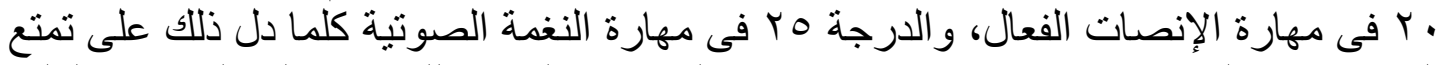

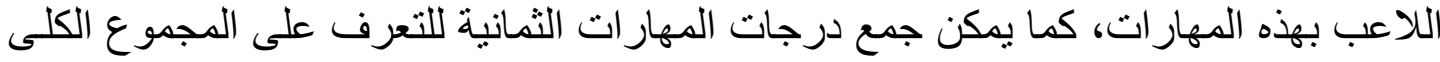

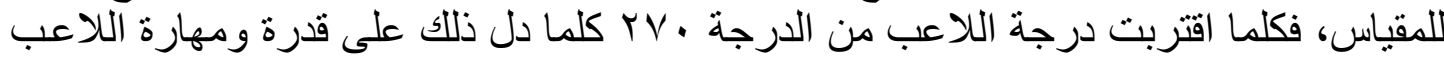
على الاتصال الجيد بزملائه المدافعين أثناء المنافسات الريات الرياضية. 
جدول(17)

الحد الأدنى والأقصى لارجات مهارات مقياس مهارات الاتصال والدرجات الكلية للمقياس

\begin{tabular}{|c|c|c|c|c|c|}
\hline \multirow{2}{*}{ الحد الأقصى } & \multirow{2}{*}{ الحد الأدنى } & \multicolumn{2}{|c|}{ العبارات } & \multirow{2}{*}{ المهارات } & \multirow[b]{2}{*}{ p } \\
\hline & & السلبية & الإيجابية & & \\
\hline$r$. & 1 & - & 7 & الحضور و اليقظة & 1 \\
\hline r. & $\varepsilon$ & 1 & $\mu$ & 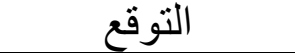 & r \\
\hline$\leqslant 0$ & 9 & $r$ & 7 & إدر الك الدور & $r$ \\
\hline $\mathrm{V}$. & $1 \varepsilon$ & $T$ & $\pi$ & التحدث و الإقناع & $\varepsilon$ \\
\hline ro & 0 & - & 0 & التعامل الايجابي & 0 \\
\hline ro & V & - & V & استخدام لغة الجسد & 7 \\
\hline$r$. & $\varepsilon$ & 1 & $r$ & الإنصـات الفعال & V \\
\hline ro & 0 & - & 0 & النغمة الصوتية & $\Lambda$ \\
\hline rV. & $0 \leqslant$ & & & المجموع & \\
\hline
\end{tabular}

بدراسة جدول(7 (1)، يتبين: الحد الأدنى والأقصى لدرجات مهارات مقياس مهارات

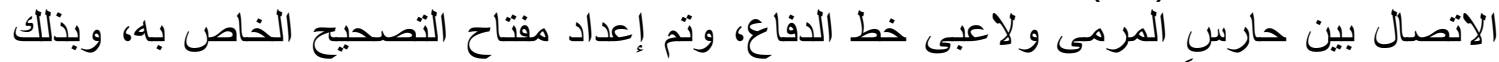

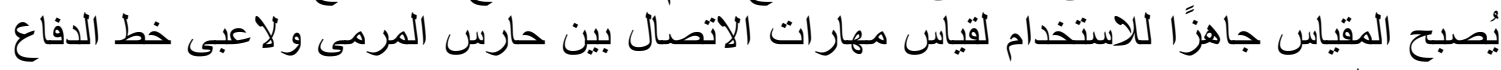

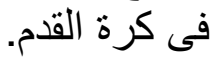

1 1/1 المعالجات الإحصائية: فى ضوء أهداف البحث والنتائج التى تم الحصول عليها تم إجراء المعالجات الإحصائية

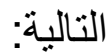
المتوسط - الانحراف المعيارى - معامل ارتباط بيرسون - معامل ارتباط سبيرمان معامل ارتباط جتمان- معامل ألفاكرونباخ.

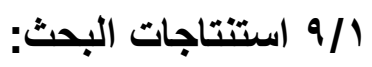

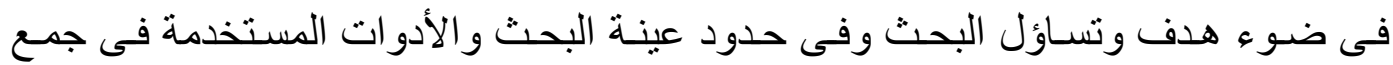
البيانات تمكن الباحث من التوصل إلى الاستنتاجات التالية:

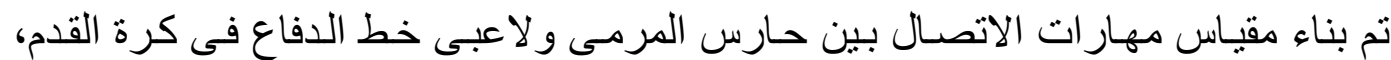

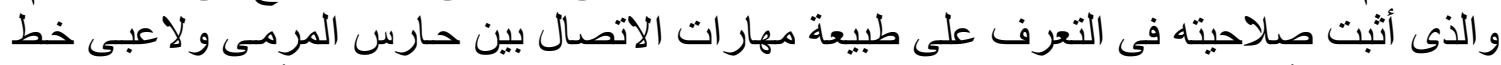

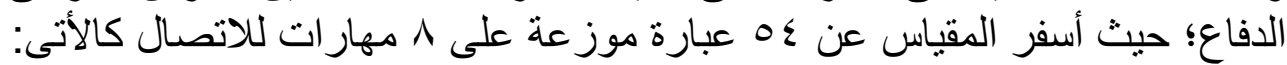

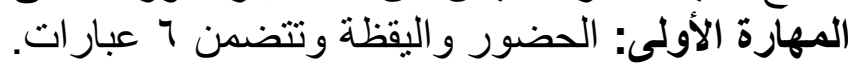
المهارة الثاتية: التوقع وتتضمن ع الاول عبار ات. 
المهــارة الثالثـة:ة إدر الك الدور وتتضمن 9 عبار ات.

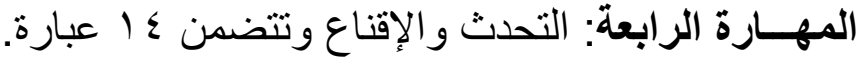

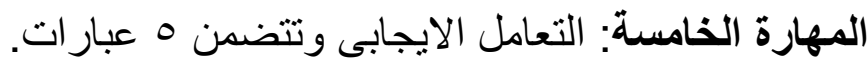

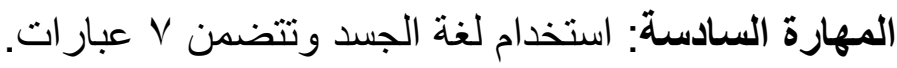

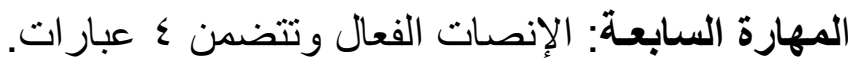

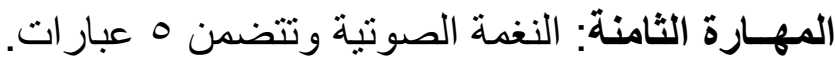

وللمقياس درجة استجابة وفقًا لميزان تقدير خماسى: دائمًا - غالبًا ــ أحيانًا - نـادرًا ـ أبدًا،

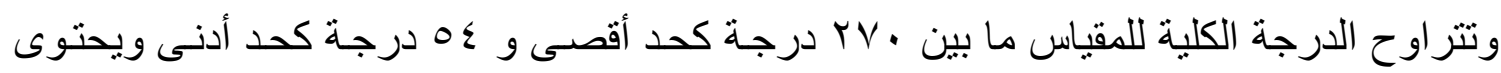

المقياس على ^^ء عبارة إيجابية، و 1 ع عبار ات سلبية.

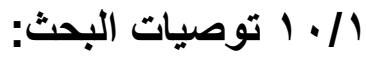

\section{فى ضوء نتائج البحث والاستنتاجات يوصى الباحث بما يلى:}

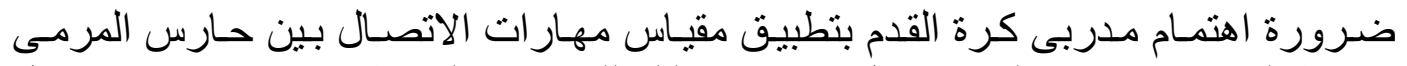

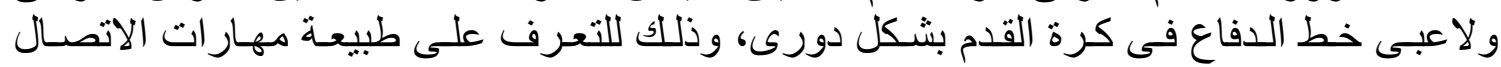
و التفاعلات الحركية بين حارس المرمى و ولاعبى خط الدفاع فورى ولى كرة القدم.

ضرورة وضع بر امج عملية وتطبيقية لتنمية وتطوير مهار ات الاتصال بين حارس المرمى و لاعبى خط الدفاع فى كرة القدم.

إجر اء المزيد من الدراسـات المشـابة لطبيعة الدر اسـة الحاليـة على مر اكز وخطوط اللعب المختلفة(خط الوسط - خط الهجوم) فى كرة القدم.

إجر اء در اسات مماثلة للار اسة الحالية لرياضات جماعية أخرى وفئات عمرية مختلفة. 


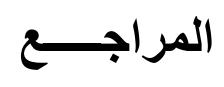

أولاً : المراجع العربية

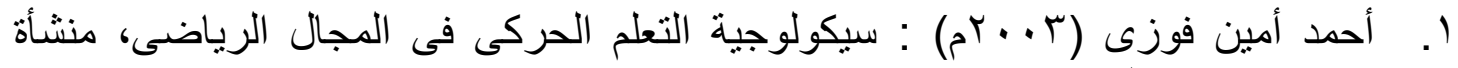

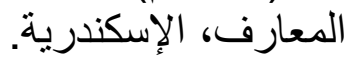

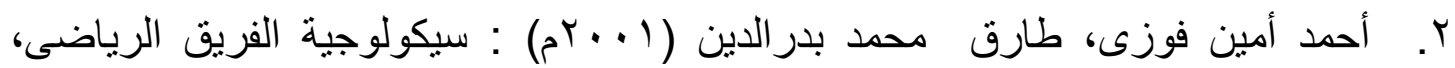

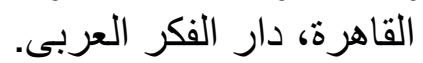

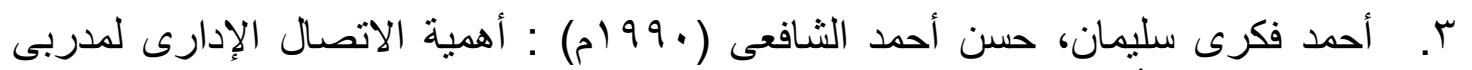

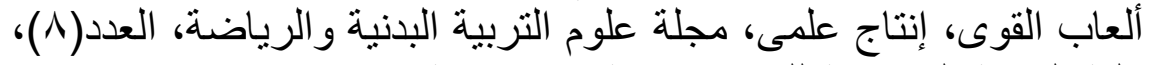

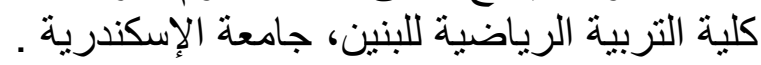

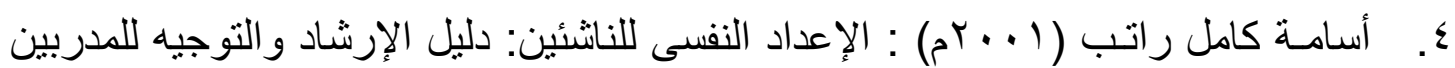

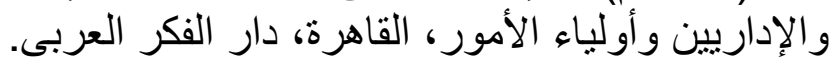

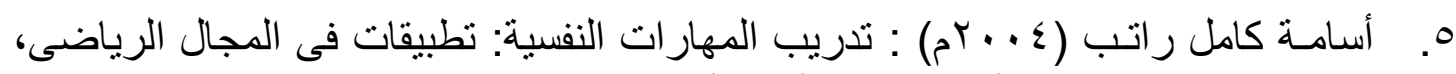

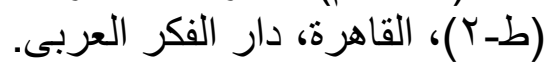

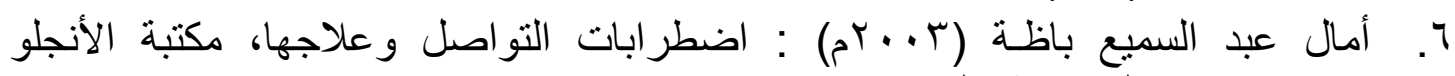

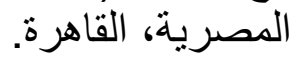

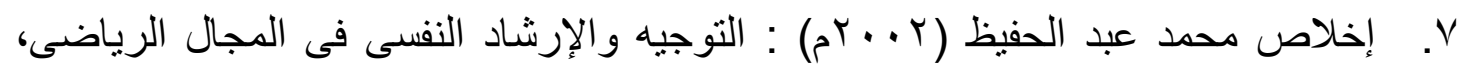
مركز الكتاب للنشر، القاهرة.

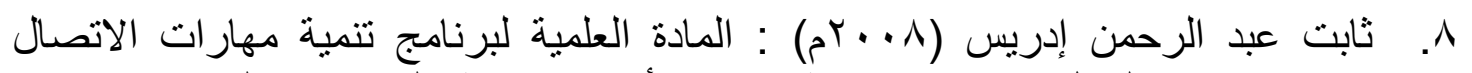

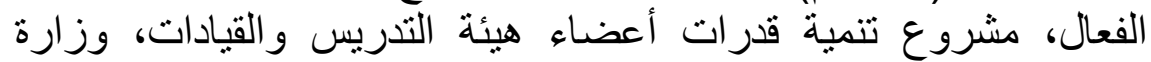
التعليم العالى، القاهرة.

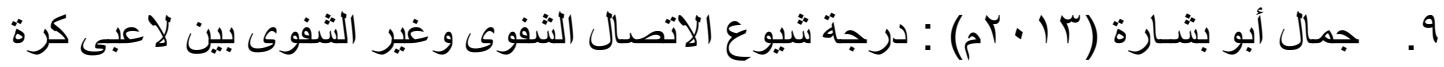

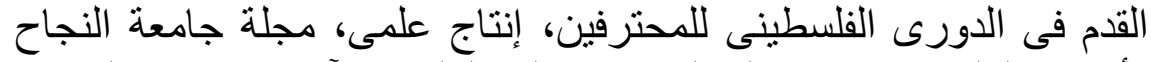

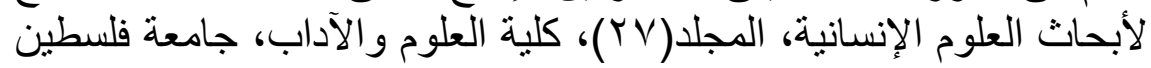
التنتية.

• ا. جهاد نبيه عبد الدحسن (r ..rم) : السمات الإرادية الميزة لمتسابقى المستويات العليا

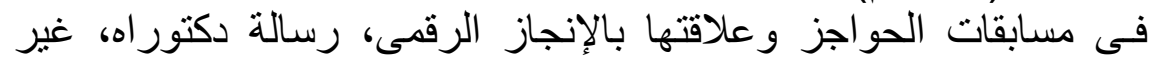

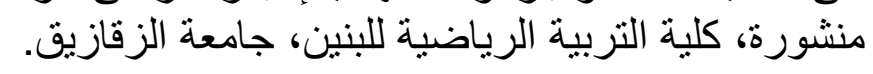

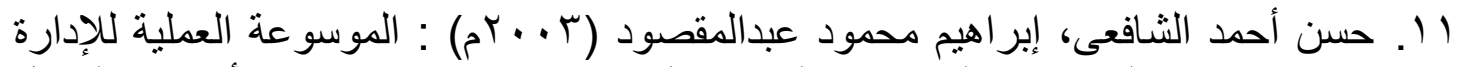

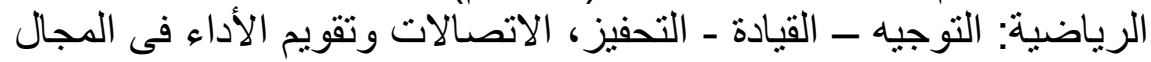
الرياضى، (ج- ؛)، دار الوفاء لدنيا الطباعة و النشر، الإسكندرية.

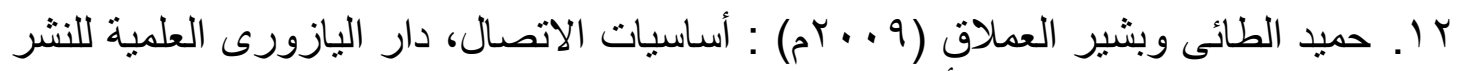

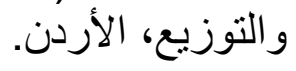




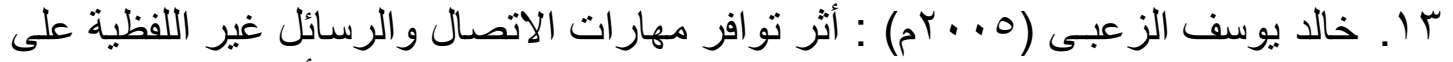

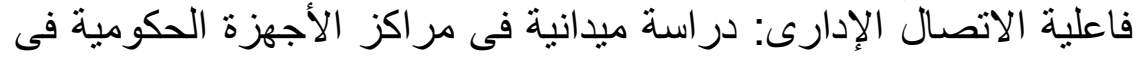

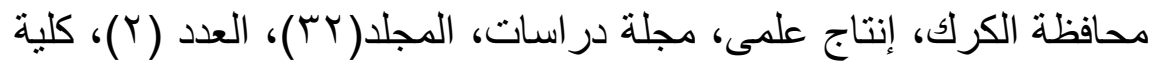

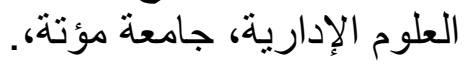

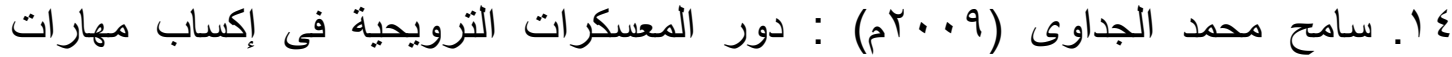

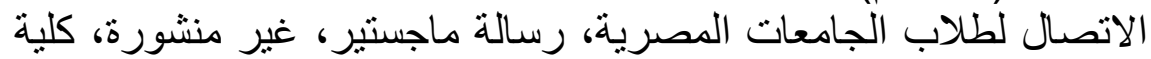

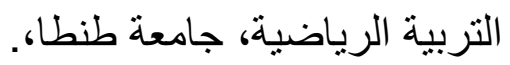

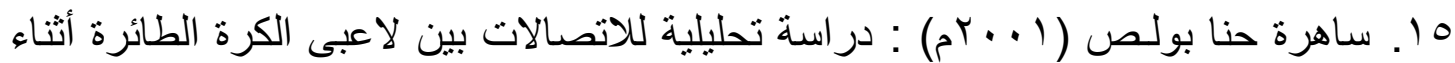

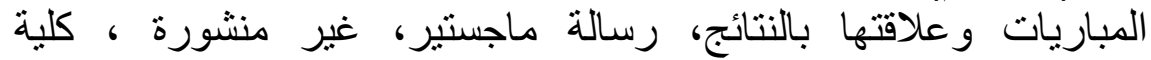
الدر اسات العليا، الجامعة الأردنية.

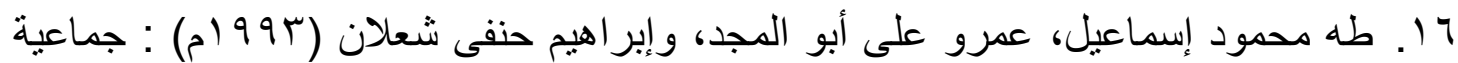
اللعب فى كرة القدم، مطابع الأهر ام التجارية، الهرئ القاهرة.

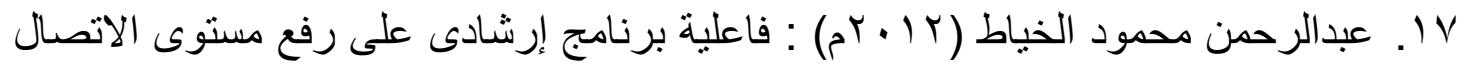

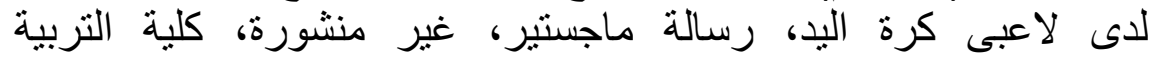

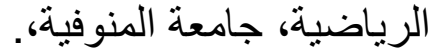

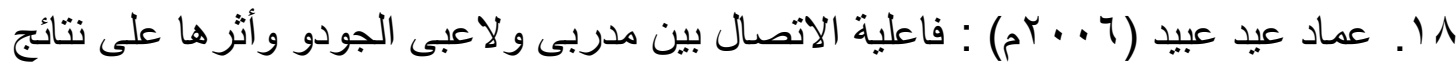

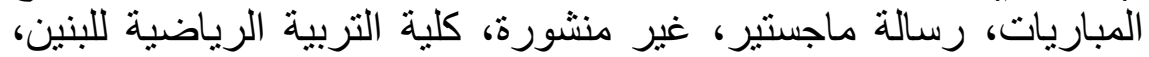

جامعة بنها.

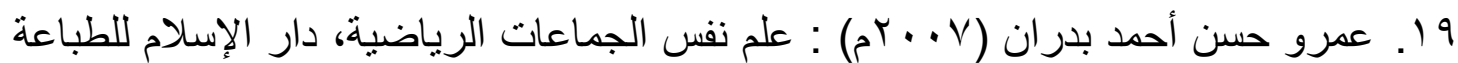

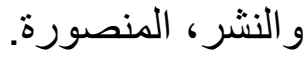

•r. . فتحى مصطفى الزيـات (999 (م) : علم النفس العام، دار الوفاء للطبع والنشر والتوزيع، المنصورة.

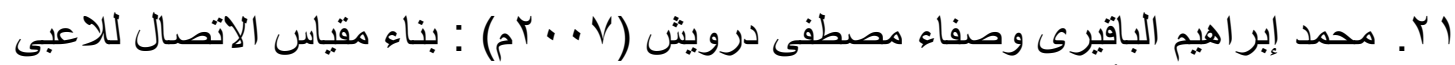

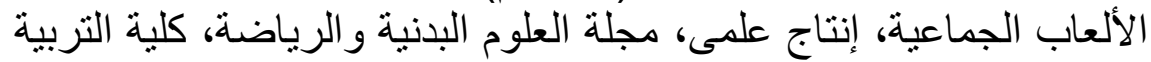
الرياضية بالسادات، جامعة المنوفية.

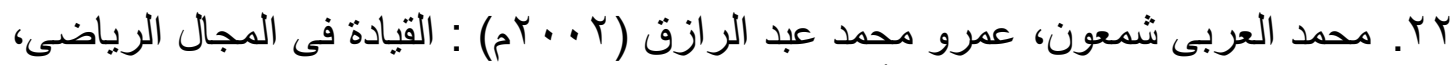
القاهرة، مكتبة الأنجلو المصرية.

rr. محمد حسن علاوى (99191م) : موسوعة الاختبارات النفسية للرياضيين، مركز الكتاب للنشر ، القاهرة .

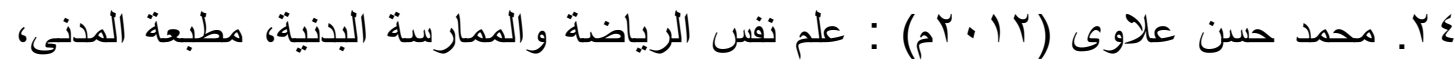

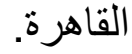

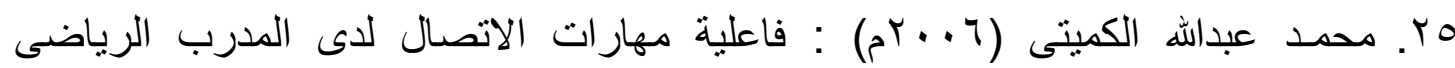

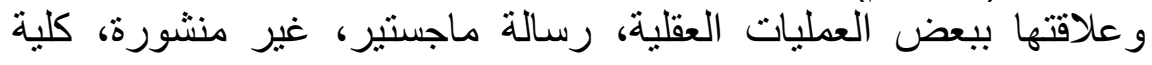

التربية الرياضية للبنين، جامعة بنها. 


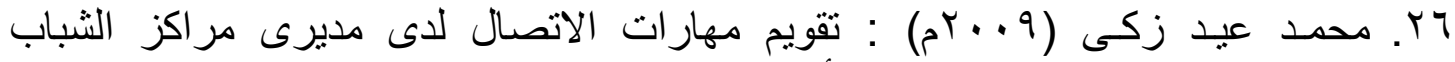

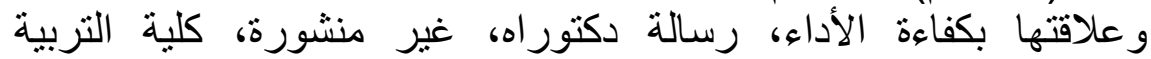
الرياضية للانين، جامعة بنهاءة الاداهُ

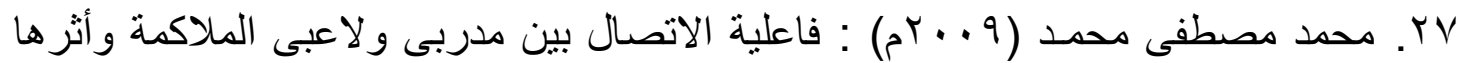

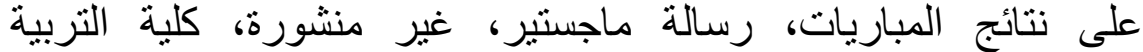
الرياضية للبنين، جامعة بنها.

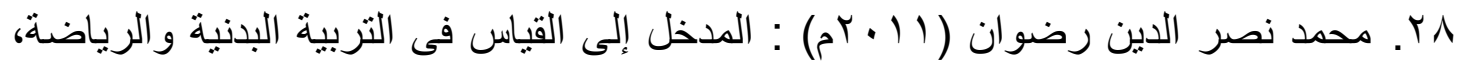
(ط-Y-(Y)، مركز الكتاب للنشر ، القاهرة.

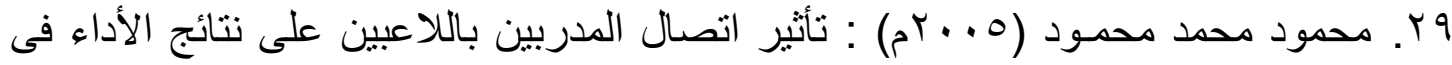

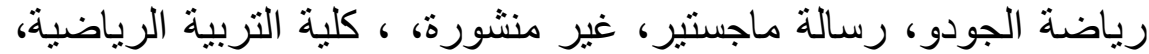

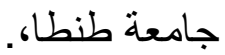

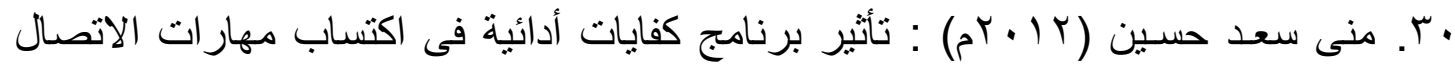

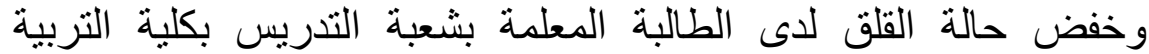
الرياضية جامعة طنطا، رسالة ماجستير، غيرلة الرية منشورة، كلية التربية

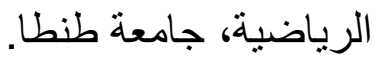

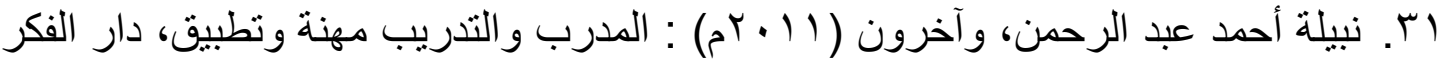

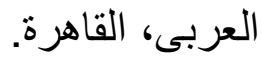

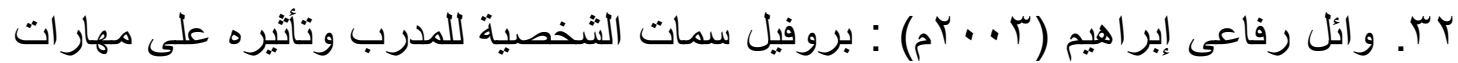

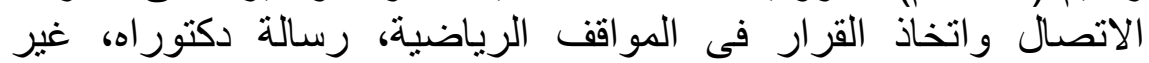

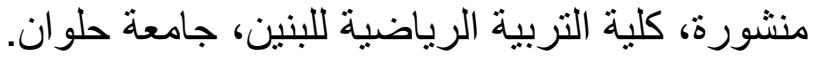

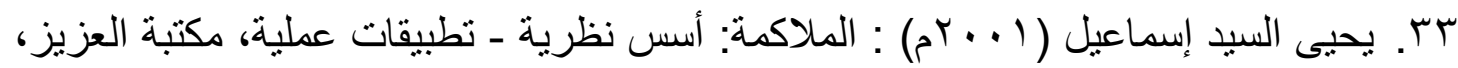

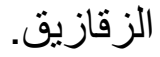

ثانياً: :المراجع باللغة الأجنبية

34. Dorothy V. Harris, Bette L. Harris : Athletes Guide to Sports Psychology leisure press. Champaign Illinois. 1994.

35. Hargie. O and Dickson. D : Skilled Interpersonal Communication Research. Theory and practice. London Rout ledge. 2004.

36. Lausic. Domago j : Explicit and implicit types of communication: A conceptualization of intra-team communication in the sport of tennis" The Florida State University. 2009.

37. Sullivan : Communication skills training for interactive sport psychologist champion. 1993. 